Article

\title{
Seafloor Characterization Using Multibeam Echosounder Backscatter Data: Methodology and Results in the North Sea
}

\author{
Alireza R. Amiri-Simkooei ${ }^{1,2, * \mathbb{C}}$, Leo Koop ${ }^{1}{ }^{\mathbb{C}}$, Karin J. van der Reijden ${ }^{3}{ }^{\mathbb{D}}$, Mirjam Snellen ${ }^{1,4}$ \\ and Dick G. Simons ${ }^{1}$ \\ 1 Acoustics Group, Faculty of Aerospace Engineering, Delft University of Technology, P.O. Box 5058, \\ 2600 GB Delft, The Netherlands \\ 2 Department of Geomatics Engineering, Faculty of Civil Engineering and Transportation, \\ University of Isfahan, 81746-73441 Isfahan, Iran \\ 3 Conservation Ecology Group, Groningen Institute for Evolutionary Life Sciences, University of Groningen, \\ P.O. Box 11103, 9700 CC Groningen, The Netherlands \\ 4 Delft University of Technology, Hydraulic Engineering, 2629 HS Delft, DELTARES, P.O. Box 177, \\ $2600 \mathrm{MH}$ Delft, The Netherlands \\ * Correspondence: a.amirisimkooei@tudelft.nl
}

Received: 29 May 2019; Accepted: 28 June 2019; Published: 30 June 2019

check for updates

\begin{abstract}
Seafloor characterization using multibeam echosounder (MBES) backscatter data is an active field of research. The observed backscatter curve (OBC) is used in an inversion algorithm with available physics-based models to determine the seafloor geoacoustic parameters. A complication is that the OBC cannot directly be coupled to the modeled backscatter curve (MBC) due to the correction of uncalibrated sonars. Grab samples at reference areas are usually required to estimate the angular calibration curve (ACC) prior to the inversion. We first attempt to estimate the MBES ACC without grab sampling by using the least squares cubic spline approximation method implemented in a differential evolution optimization algorithm. The geoacoustic parameters are then inverted over the entire area using the OBCs corrected for the estimated ACC. The results indicate that a search for at least three geoacoustic parameters is required, which includes the sediment mean grain size, roughness parameter, and volume scattering parameter. The inverted mean grain sizes are in agreement with grab samples, indicating reliability and stability of the proposed method. Furthermore, the interaction between the geoacoustic parameters and Bayesian acoustic classes is investigated. It is observed that higher backscatter values, and thereby higher acoustic classes, should not only be attributed to (slightly) coarser sediment, especially in a homogeneous sedimentary environment such as the Brown Bank, North Sea. Higher acoustic classes should also be attributed to larger seafloor roughness and volume scattering parameters, which are not likely intrinsic to only sediment characteristics but also to other contributing factors.
\end{abstract}

Keywords: multibeam echosounder; seafloor sediment classification; geoacoustic inversion; angular calibration curve; least squares cubic spline approximation

\section{Introduction}

High-resolution knowledge of the morphology and sediment composition of the seafloor is in high demand for many offshore activities. Multibeam echosounders (MBESs) have been increasingly used for seafloor characterization in the last two decades. They can provide full-coverage bathymetry and backscatter data in a reasonable amount of time at moderate costs. The bathymetry data provide 
insight into seafloor topography and morphology, while the backscatter data are mainly used to gain insight into the seafloor sediment composition. We address the latter issue in this contribution.

Previous and ongoing research in seafloor sediment classification using MBES backscatter data have yielded a variety of methods. These include image- and object-based classification approaches [1-4], classification based on backscatter angular response curves [5-7], statistical clustering algorithms [8,9], principal component analysis of possibly both bathymetry and backscatter data [10-13], and quantitative approaches that predict the sediment composition $[14,15]$. With the recent development of multispectral MBES systems, seafloor classification using multi-frequency bathymetry and backscatter data is currently an active field of research [16-18]. Another method to classify seafloor sediment based on backscatter data is the Bayesian classification method developed by Simons and Snellen [19] and elaborated in more detail by Amiri-Simkooei et al. [20]. It employs backscatter data at a specific beam at low grazing angle, and fits a series of Gaussian functions to the histogram of the measured backscatter at that angle. Each Gaussian probability density function (PDF) represents then one acoustic class (AC). Grab samples are required to link the acoustic classes to sediment types.

Modeling the angular response curve (ARC) is also one of the approaches frequently used for seafloor classification. Given the signal frequency, there exist physics-based models that predict the backscatter as a function of grazing angle and sediment type. The model presented by Jackson et al. [21] states that the total backscatter strength is a combination of the interface roughness scattering and volume scattering. The complication is, however, that the received backscatter curve of MBESs, as a function of angle, is not calibrated and hence subject to variations. The angular calibration curve (ACC) is therefore to be applied to the received backscatter. The ACC is usually determined by the calibration of the MBES in flat areas, having homogenous sediment types of known grain size values. This is achieved through the application of the angular range analysis (ARA) to the measured backscatter data [6], as applied in seafloor characterization by [22,23].

The above methods require grab samples to characterize sediment types. This can be a requirement either at the calibration stage of the MBES or when assigning acoustic classes to sediment types (see [24]). Here, we propose a methodology that diminishes the need for grab samples. For this, we assume that the main contributing factor to backscattering is the marine sediment. There are however other factors influencing the backscatter such as macrofauna along with their bioturbations, vegetation, shallow gas and bacterial mats. The inverted parameters can be affected by such unaccounted factors. Therefore, our methodology aims at diminishing the need for sediment grab samples, whereas other fields of applications—e.g., marine ecology and biology—would still require ground truthing data for their seafloor characterization-habitat mapping for example.

Having the available physics-based models, one can predict the backscatter data for different sediment types, frequencies, and incident angles. For our application, we assume the Applied Physics Laboratory of the University of Washington (APL-UW) model to be valid [25]. Based on this model, given the frequency of the multibeam system, the angular response curve is affected by two main factors: (1) the sediment type, and (2) the angular calibration effect as a function of incident angle (angular calibration curve). The former is not restricted to the sediment grain size distribution only but also to other geoacoustic parameters such as the interface roughness parameter and volume scattering parameter.

To estimate the calibration curve without grab sampling, we employ cubic spline functions. Piecewise spline functions play an important role in approximating real data in many engineering applications. We propose a method to approximate the calibration curve of MBESs by employing a series of cubic spline polynomials connected to each other at some known knots. The unknown coefficients of these polynomials are to be estimated using the least squares cubic spline approximation (LS-CSA) method. Having the angular calibration curve available, an inversion procedure can be implemented to estimate the geoacoustic parameters, such as mean grain size, seabed roughness, and volume scattering. 
The remainder of this paper is structured as follows. Section 2 describes the LS-CSA theory and its application to the sonar system calibration. Section 3 treats the methodology applied to estimate the sonar calibration curve and perform a geoacoustic inversion using an optimization method. Section 4 applies the method to a MBES data set collected in the Brown Bank area of the North Sea in 2017. The discussions of the results are presented in Section 5. We draw a few conclusions in Section 6.

\section{Least Squares Cubic Spline Approximation (LS-CSA)}

\subsection{Background and Objectives}

Fitting a curve like a polynomial function in one-dimensional (1D) space to a set of scattered data points is a commonly encountered problem. One can use either interpolation or approximation to obtain the function values at specific intermediate points, depending on the nature of the problem at hand. When the data are contaminated with random noise-backscatter data, for instance-approximation provides more accurate results than interpolation. Both interpolation and approximation can be accomplished by using high-order polynomial functions. An alternative is to use a spline function, consisting of piecewise low-order polynomial segments connected together at a few known knots under some continuity conditions [26-28]; a knot is a point at which the two pieces are connected to each other. The spline functions are preferred over the high-order polynomials because they avoid the problem of high oscillations of the approximated function, known as Runge's phenomenon [29].

Spline polynomials can be made by an arbitrary degree. Splines of order $p$ have continuous derivatives up to the order $p-1$ at the boundaries of the joined curves. For the third-order polynomial splines $(p=3)$, called cubic splines, the first and second derivative are thus continuous at the knots $[30,31]$. An approximating spline does not necessarily pass through the knots, but it only gets as close as possible to the knots in the least squares sense [32-34]. This method often requires redundant measurements to enhance the precision and reliability of the fitting procedure. The theory and application of the least squares cubic spline approximation (LS-CSA) are presented in [35]. This theory is used to estimate the ACC of MBES without grab sampling.

The observed backscatter strength of MBESs is a function of the signal frequency, grazing angle, and sediment type. The angular dependence of received backscatter data in combination with an established seafloor interaction model allows for an inversion to estimate the geoacoustic parameters. There is one complication; the calibration of the sonar systems. Therefore, an important step in the use of a geoacoustic inversion procedure is estimating the calibration curve of the sonar system. This is usually achieved through the application of angular range analysis (ARA) method proposed by Fonseca and Mayer [6]. We propose a new method that preserves the backscatter angular information but diminishes the need for reference areas or grab samples. This methodology is based on the intrinsic angular dependence of the backscatter to the sediment types, which provides a tool for sonar calibration and therewith seafloor characterization.

We hypothesize that the calibration curve of the sonar system is a function of signal frequency and grazing angle. The difference between the observed $\left(B S^{\circ}\right)$ and modeled $\left(B S^{m}\right)$ backscatter data is considered to be the calibration curve. One then has

$$
C(f, \theta)=B S^{o}(f, \theta, A C)-B S^{m}\left(f, \theta, M_{z}\right)
$$

where $f$ is the signal frequency, $\theta$ is the incident angle (complementary pair of grazing angle $\phi=90-\theta$ ), $A C$ is the acoustic class number obtained from the Bayesian classification method proposed by [19] (see Section 3.1), $M_{z}$ (This is for notation convenience; in principle other geoacoustic parameters can be used.) is the mean grain size of sediment. For a given frequency $f$, the above equation simplifies to

$$
C(\theta)=B S^{o}(\theta, A C)-B S^{m}\left(\theta, M_{z}\right)
$$


which is the basis model considered to estimate the calibration curve. The preceding equation, for the incident angle $\theta_{j}, j=1, \ldots, J$, the acoustic class $A C_{i}, i=1, \ldots, I$, and the mean grain size $M_{z k}, k=1, \ldots, K$, can be rewritten as

$$
C\left(\theta_{j}\right)=B S^{o}\left(\theta_{j}, A C_{i}\right)-B S^{m}\left(\theta_{j}, M_{z k}\right)
$$

Although $A C_{i}$ and $M_{z k}$ are closely related, there is not necessarily a one-to-one correspondence between the acoustic classes and the mean grain sizes [36]. Based on the observed-minus-modeled (O-M) backscatter data $y_{j}=B S^{o}\left(\theta_{j}, A C_{i}\right)-B S^{m}\left(\theta_{j}, M_{z k}\right)$, we may follow the method elaborated in the next section to estimate the calibration curve $C(\theta)$ of the sonar system.

Each acoustic class $A C_{i}, i=1, \ldots, I$ is linked to three geoacoustic parameters in the optimization method. They include the mean grain sizes $M_{z}$, the spectral strength (roughness parameter) $w_{2}$ and the volume scattering parameter $\sigma_{2}$ [21]. The parameter $w_{2}$ is the strength of bottom relief spectrum $\left(\mathrm{cm}^{4}\right)$ at the wavenumber of $2 \pi / \lambda=1 \mathrm{~cm}^{-1}$, whereas the parameter $\sigma_{2}$ is the ratio of sediment volume scattering cross section to sediment attenuation coefficient. The optimization method searches for the above parameters, which were constrained to $-1 \leq M_{z} \leq 9,0.001 \leq w_{2} \leq 0.01$ and $0.0001 \leq \sigma_{2} \leq 0.02$ [25]. For $I$ acoustic classes, this will then introduce $3 I$ unknown coefficients to be estimated in the optimization process. We will refer to this as 'one independent run' in the subsequent sections.

\subsection{Principle of LS-CSA}

We now present the principle of LS-CSA to fit piecewise cubic polynomials to a number of consecutive data points. Let $\left(\theta_{j}, y_{j}\right)$ be $m$ points, where $\theta_{j}$ is a given incident angle and $y_{j}$ is its corresponding observed-minus-modeled (O-M) backscatter data. The observation vector $y=$ $\left[y_{1}^{(1)}, \ldots, y_{J}^{(1)}, \ldots, y_{1}^{(I)}, \ldots, y_{J}^{(I)}\right]$, stacks the O-M backscatter data of all acoustic classes to a single $m$-vector, where $m=I \times J$. We assume $\theta_{1}=-65^{\circ}, \theta_{2}=-64.5^{\circ}, \theta_{3}=-64^{\circ}, \ldots$, etc., indicating a bin size of $0.5^{\circ}$ at which the O-M backscatter data are available.

The consecutive pieces are joined together at some intermediate points $\vartheta_{i}, i=0,1, \ldots p$, known as knots, such that the first and second derivatives of the fitted curves are also continuous at these points. Without the loss of the generality, we divide the total angular range into $p$ equally-spaced pieces. For example, the angular range can be divided into $p=26$ pieces at $\vartheta_{0}=-65^{\circ}, \vartheta_{1}=-60^{\circ}, \ldots, \vartheta_{26}=$ $+65^{\circ}$, indicating a bin size of $5^{\circ}$ at which the pieces are connected to each other.

The piecewise cubic spline function, made of the $p$ pieces of all cubic curves glued together, is of the form

$$
C(\theta)=\left\{\begin{array}{cc}
C_{1}(\theta)=a_{1}+b_{1} \theta+c_{1} \theta^{2}+d_{1} \theta^{3}, & \theta \in\left(\vartheta_{0}, \vartheta_{1}\right) \\
C_{2}(\theta)=a_{2}+b_{2} \theta+c_{2} \theta^{2}+d_{2} \theta^{3}, & \theta \in\left(\vartheta_{1}, \vartheta_{2}\right) \\
C_{p}(\theta)=a_{p}+b_{p} \theta+c_{p} \theta^{2}+d_{p} \theta^{3}, & \theta \in\left(\vartheta_{p-1}, \vartheta_{p}\right)
\end{array}\right.
$$

fitted to every $m_{i}, i=1, \ldots, p$ consecutive data points in the least squares sense $\left(m=\sum_{i=1}^{p} m_{i}\right)$. The unknown parameters $\left(a_{i}, b_{i}, c_{i}, d_{i}\right), i=1, \ldots, p$, the coefficients of the cubic polynomials, are to be estimated. Given in total $m$ points, there are $m$ observation equations and $4 p$ unknown coefficients. The piecewise polynomials in Equation (4) make a linear model of observation equations as $\mathrm{E}(y)=A x$, where $\mathrm{E}$ is the expectation operator, $y$ is the $m$-vector of O-M observations, $x$ is the $n$-vector of the unknowns, and $A$ is the $m \times n$ design matrix, $n=4 p$. The coefficients of the polynomials are to be estimated through this linear model using the least squares method.

There are also some continuity constraints for the above cubic polynomials. These constraints, required to ensure that the function values and their first and second derivatives are continuous at the interior knots, are of the form

$$
\begin{aligned}
& C_{i}\left(\vartheta_{i}\right)=C_{i+1}\left(\vartheta_{i}\right) \\
& C_{i}^{\prime}\left(\vartheta_{i}\right)=C_{i+1}^{\prime}\left(\vartheta_{i}\right), i=1, \ldots, p-1 \\
& C_{i}^{\prime \prime}\left(\vartheta_{i}\right)=C_{i+1}^{\prime \prime}\left(\vartheta_{i}\right)
\end{aligned}
$$


where $\vartheta_{i}$ is the point at which the two consecutive pieces are connected to each other. There exist a total of $3 p-3$ hard constraints, to be added to the system of equations. The redundancy of the model is then $d f=m-p-3$. This will then make a constrained model of the form $C^{T} x=0$, where $C$ is an $n \times q$ constraint matrix $(q=3 p-3)$.

To solve the observation equations with the hard constraints, we may use the following representation of the functional model [34]

$$
\mathrm{E}(y)=A x, C^{T} x=0, \quad \mathrm{D}(y)=Q_{y}
$$

where $\mathrm{D}$ is the dispersion operator and $Q_{y}$ is the covariance matrix (if any) of the O-M observations $y$. The unknown coefficients $x$ can be estimated by the least squares method subject to hard constraints as

$$
\hat{x}=C^{\perp}\left(C^{\perp T} N C^{\perp}\right)^{-1} C^{\perp T} u
$$

where $N=A^{T} Q_{y}^{-1} A, u=A^{T} Q_{y}^{-1} y$, and $C^{\perp}$ is a basis matrix that spans the null space of $C^{T}$.

There is an alternative method to the above constrained least squares problem in which the constraints are directly implemented in the cubic polynomials. This can be achieved by using the basis-spline (B-spline) theory. A spline function of a given degree can in principle be expressed as a linear combination of B-splines of that degree for which their continuity conditions are automatically fulfilled at the knots. Therefore, one does not require imposing the constraints $C^{T} x=0$ directly to the problem, and the weighted least squares can be used without the constraints. Expressions for the polynomial pieces of the B-splines can be derived by means of the Cox-de Boor recursion formula [37]. The above two methods, based on either the constrained least squares or the B-splines, have both been used independently and identical results were obtained.

\section{Seafloor Characterization Using Proposed Method}

We propose a three-step method to characterize seafloor sediments. The subsequent sections give an overview of these steps in more details.

\subsection{Application of Bayesian Method}

For a sufficient number of scatter pixels within the beam footprint, the backscatter data are assumed to be normally distributed. Looking at a given incident angle, this method fits I Gaussian PDFs, each representing one acoustic class, to the histogram of the backscatter values

$$
f\left(y_{j} \mid x\right)=\sum_{i=1}^{I} c_{i} \exp \left(-\frac{\left(y_{j}-\mu_{i}\right)^{2}}{2 \sigma_{i}^{2}}\right)
$$

where $y_{j}$ is the backscatter value at bin $j(j=1, \ldots, M)$ with $M$ being the number of bins of the backscatter histogram. For each PDF, the triple $\left(\mu_{i}, \sigma_{i}\right.$ and $\left.c_{i}, i=1, \ldots, I\right)$ indicates the mean, standard deviation and contribution of that PDF, respectively. The number of PDFs is determined in an iterative fitting procedure using the chi-squared goodness-of-fit test statistics

$$
\chi^{2}=\sum_{j=1}^{M} \frac{\left(n_{j}-f\left(y_{j} \mid x\right)\right)^{2}}{\sigma_{n_{j}}^{2}}
$$

where $n_{j}$, the number of backscatter measurements per bin $j$, has a Poisson distribution with the variance $\sigma_{n_{j}}^{2}=n_{j}$. The test statistic has a chi-squared distribution with $v=M-3 I$ degrees of freedom. Increasing $I$ will usually decrease $\chi^{2}$. The value of $I$ at which no significant improvement on the above statistic is obtained, is the optimal value of $I$. The above $I$ PDFs introduce $I$ hypotheses as $H_{i}, i=1, \ldots, I$, corresponding to I seafloor acoustic classes. 
For detailed information, the reader is referred to [19]. For applications of the method on multiple datasets with varying conditions we refer to $[13,20,38]$.

\subsection{Estimation of Angular Calibration Curve}

The acoustic classes of the previous section can be attributed to sediment characteristics such as mean grain size $[19,20,39]$, with higher acoustic classes generally corresponding to larger sediment grain sizes. However, recent research showed that the acoustic classes do not necessarily depend on the mean grain sizes only [36]. This indicates that other sediment characteristics should also be taken into account. The model proposed by Jackson et al. [21] suggests that the backscatter is modeled as the sum of two different processes, i.e., the seabed-water interface and seabed volume scattering. The three model parameters that control these two processes are the acoustic impedance (sound speed and density ratios of sediment to water), the seafloor roughness and the sediment volume scattering parameter [6]. There are empirical models that relate acoustic impedance to the mean grain size $M_{z}$, expressed in phi $(\phi)$ units, see [40]. For the roughness parameter $w_{2}$ and the volume scattering parameter $\sigma_{2}$, only weak relations with $M_{z}$ are found, with considerable variations (APL-UW model, [25]). Hence, $\sigma_{2}$ and $w_{2}$ are not much correlated with $M_{z}$. Optimization is therefore performed by using the three parameters $M_{z}, w_{2}$, and $\sigma_{2}$. They are estimated both in the calibration stage and also when estimating the geoacoustic parameters of the entire area after implementing the corrections following the angular calibration curve (ACC).

The backscatter data of all identified classes, over the entire angular range, are used to estimate the calibration curve. The O-M backscatter data are used to fit a cubic spline function, as described in Section 2.2. This is complicated because the O-M data cannot directly be obtained, as the modeled BS is a function of geoacoustic parameters $M_{z}, w_{2}$, and $\sigma_{2}$, which are assumed to be unknown. Therefore, the calibration curve and the geoacoustic parameters of the selected curves are to be estimated in an optimization process, achieved by the differential evolution (DE) method (see [41]). This method, as a metaheuristics method, optimizes a problem in an iterative manner by improving a candidate solution with regard to a given measure of quality. This method has been successfully applied to a few geoacoustic inversion problems in the last decade [42,43].

To enhance the stability and reliability of the estimation process, we applied the above optimization procedure to several independent runs (say 1000 runs). For each independent run, the following steps were taken. The BS curves of identified classes, averaged over a few consecutive pings, are randomly selected in the entire area. The above DE optimization procedure is implemented to estimate the calibration curve $C(\theta)$ and the geoacoustic parameters $M_{z}$, $w_{2}$, and $\sigma_{2}$ of the selected classes. This procedure results in several estimates for the calibration curve. The average over all independent runs is considered to be the final calibration curve $C(\theta)$.

\subsection{Model Inversion Using Optimization Method}

Given the calibration curve $C(\theta)$, the final step is to implement the optimization method and estimate the geoacoustic parameters $M_{z}, w_{2}$, and $\sigma_{2}$ for the entire area. The backscatter curve is averaged over a few pings to create the observed BS. The model $y=\mathrm{O}-\mathrm{M}=C(\theta)=A x$ of the previous section is now reformulated as $\mathrm{O}-C(\theta)=\mathrm{O}-A x=\mathrm{M}$, indicating first to compensate for the angular calibration effect and then to implement the optimization procedure for the geoacoustic parameters inversion. For the observed mean backscatter curve, Equation (3) is now reformulated to

$$
B S^{o}\left(\theta_{j}\right)-C\left(\theta_{j}\right)=B S^{m}\left(\theta_{j}, M_{z k}\right)
$$

The left-hand side of this equation is the observed angular curve, corrected for the calibration curve, and the right hand side is the modeled backscatter curve. It is a function of geoacoustic parameters to be estimated through the optimization process. The above DE optimization procedure is then implemented to estimate the geoacoustic parameters $M_{z}$, $w_{2}$, and $\sigma_{2}$ of the selected backscatter curve. 
To have a better spatial resolution, this process is separately implemented for the port $\left(-65^{\circ} \leq \theta \leq 0^{\circ}\right)$ and starboard $\left(0^{\circ} \leq \theta \leq 65^{\circ}\right)$ sides of the sonar.

\section{Application to MBES Dataset in Brown Bank}

\subsection{Study Area and Data Description}

The Brown Bank, located in the North Sea, is about $85 \mathrm{~km}$ off the coast of the Netherlands, and is between the UK and the Netherlands. The dominant bathymetric features of this area are sand banks, being tens of meters high and having wavelengths of $5-10 \mathrm{~km}$. The most dominant sand bank in this area is called the Brown Bank [44]. It runs north and south, with a water depth on the crest of the bank of $\sim 19 \mathrm{~m}$, and a water depth in the troughs on either side being $\sim 45 \mathrm{~m}$. There are two other sizes of periodic bed forms present: sand waves, with a wavelength of $\sim 200 \mathrm{~m}$, height difference of a few meters, and migration rate of several meters per year; and megaripples, with a wavelength of $\sim 15 \mathrm{~m}$, height difference of a $\sim 1 \mathrm{~m}$, and migration rate is higher than sand waves. Seafloor classification on megaripples has already been implemented by [36]. We focus here only on the large-scale classification and sedimentary composition of the sand bank.

The uppermost $6 \mathrm{~m}$ of sediment of Brown Bank comprises early to late Holocene deposits, mostly sands [45]. The surrounding seabed is strongly scoured consisting of fluvio-terrestrial sediments, beneath which lie locally fluvioglacial and fluvial sand, containing some gravel $[46,47]$. Van Dijk et al. [48] show that the troughs of the Brown Bank consist of muddy sediments mixed with gravel and shell fragments and the crests contain well sorted medium sand.

The Brown Bank was surveyed by the Royal Netherlands Institute for Sea Research (NIOZ) vessel, the Pelagia, from 27 October to 03 November 2017. The survey was performed with a hull-mounted Kongsberg EM 302 MBES system. The settings were locked on a central frequency of $30 \mathrm{kHz}$ and $2^{\circ}$ and $1^{\circ}$ beam opening angles in the across and along track directions, respectively. The pulse length was set to $750 \mu$ s. The beam coverage of 432 beams was set to equidistant (vs. equiangular). A swath opening angle of $130^{\circ}$ was used, with port and starboard coverage both being $65^{\circ}$. The EM 302 has a sensitivity resolution of $0.1 \mathrm{~dB}$. Bathymetry, backscatter, and water column data were recorded using Kongsberg's native Seafloor Information System (SIS) software. A Seapath global positioning system (GPS) and motion reference unit (MRU) provided position and motion correction information. MBES data were corrected for roll, heave, and yaw. Figure 1 shows the bathymetry of the survey area in the Brown Bank along with ground truth data locations.

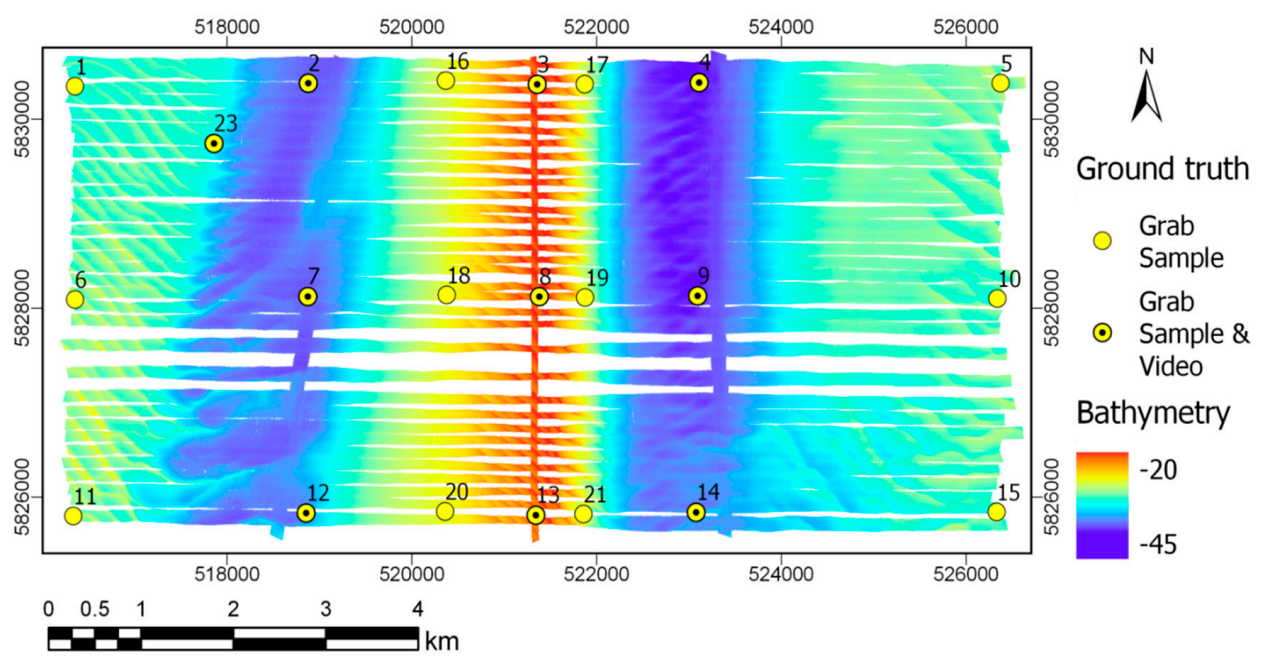

Figure 1. Bathymetry of Brown Bank extracted from multibeam echosounder data; yellow circles are positions having grab samples, yellow circles with dots indicates grab samples plus video data. 
There were two kinds of ground-truthing data; grab samples and video transects. Twenty-two grab sample locations were selected, with 21 of these falling on approximately a regular grid (Figure 1). At each location three replicate samples were taken resulting in a total of 66 grab samples, which were acquired with a $30 \mathrm{~cm}$ Box Core. From these Box Core data, subsamples have been taken for particle size analysis (PSA) for which they were successively sieved over 4, 2, and $1 \mathrm{~mm}$ sieves. The weights of these fractions were measured. The grain size distribution of the fraction smaller than $1 \mathrm{~mm}$ was determined by means of laser diffraction with a Malvern Mastersizer 2000 (Malvern Instruments, Worcestershire, UK). The videos of the seabed were collected along $150 \mathrm{~m}$ transects with a towed video camera, as described in [36]. The video camera was set to view the seabed just in front of the frame, and the NIKON camera faced down and was set to automatic time-lapse, at an interval of $10 \mathrm{~s}$. During video operations, the vessel had a speed of $\sim 0.1 \mathrm{~m} / \mathrm{s}$, while a constant height above the seabed was manually maintained, based on live-view of the video camera.

\subsection{Bayes Classification Results}

The Bayesian classification method is now applied to the above-described backscatter data set. An averaging procedure was implemented to the bathymetry and backscatter data. For each survey line, a regular grid of $2 \times 2 \mathrm{~m}$ on the seafloor was considered to implement the averaging. This indicates that in principle one includes more angles around the central beam angle. The surface patches may also take into account averaging over a few consecutive pings. Having a small surface patch will not change the statistical characteristics of backscatter values significantly and hence its averaging is allowed for our application. Furthermore, the use of these surface patches is threefold. First, it allows the outlying backscatter values to be identified and removed in the averaging procedure. Second, the averaging procedure assures the validity of the central limit theorem for the normality assumption of the backscatter data; it also reduces the backscatter noise and fluctuations. Third, the bottom slopes can significantly affect the backscatter data and the grazing angle. Having the above surface patches allows to compute the along and across track slopes and hence correct for the backscatter values and the grazing angles (see $[20,36])$. The classification method is then applied to the corrected backscatter data.

The number of seafloor classes is unknown and needs to be determined based on the Bayesian method described in the previous section. This is achieved by increasing the number of Gaussian functions to well describe the histogram of the averaged backscatter strength values. The value of $I$ at which either the test statistic falls below the critical value or no further significant decrease in the test statistic is obtained is the optimal value for $I$. This value was determined to be $I=4$ for the data considered. The beam angles used to implement the Gaussian fitting were $\theta=60^{\circ}, 62^{\circ}$, and $64^{\circ}$ for both the port and starboard sides (see [36]). The study area shows low acoustic classes (green and yellow) on the crest and high acoustic classes (orange and red) in the troughs (Figure 2). 


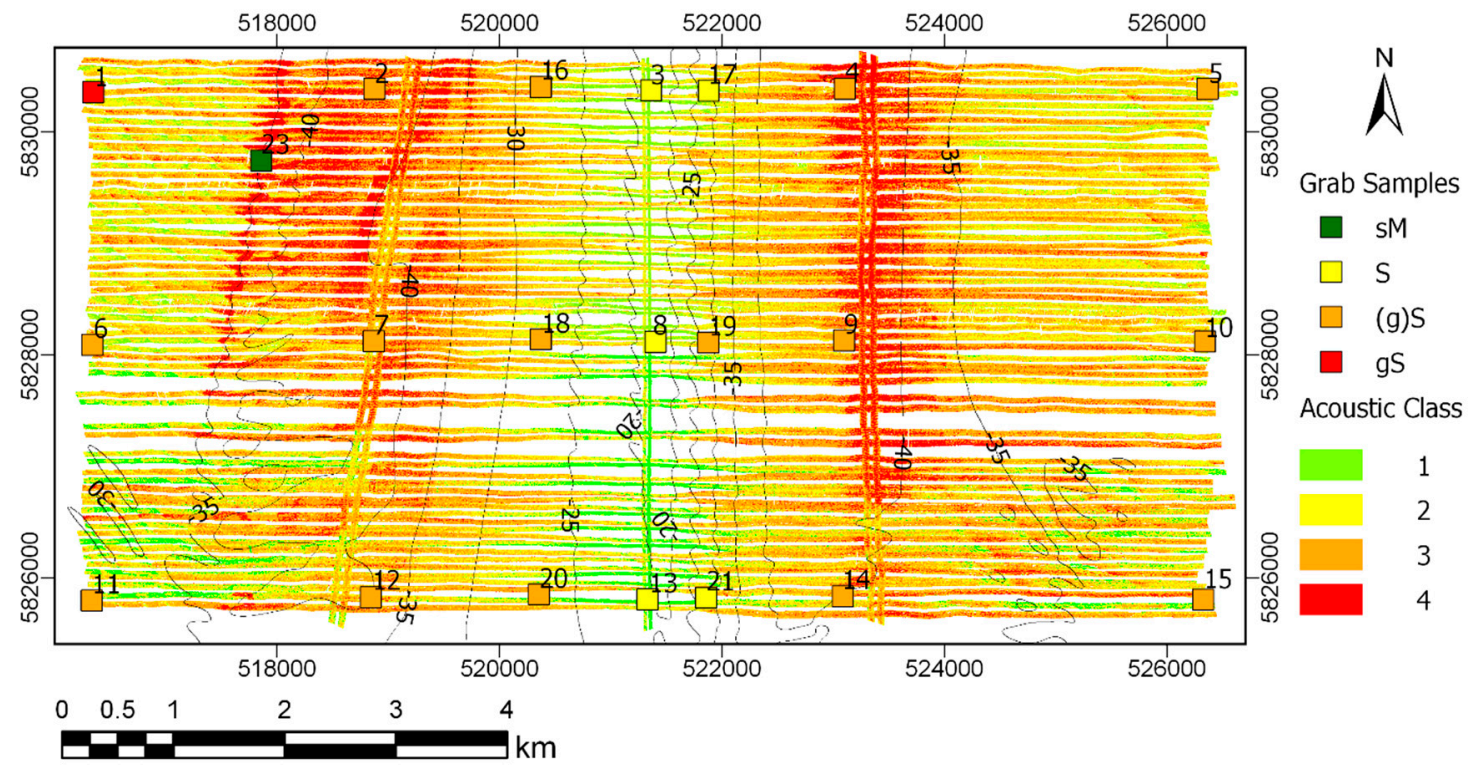

Figure 2. Bayesian classification map along with grab samples based on Folk scheme. Four acoustic classes ranging from lowest backscatters (green) to highest values (red), figure from Koop et al. [36].

\subsection{Calibration of $M B E S$}

The procedure provided in Section 3.2 is now implemented to estimate the backscatter calibration curve. The backscatter curves are subject to high variations owing to noise. The fluctuation is reduced by the along-track averaging prior to analysis for which 30 consecutive pings were used. The estimation process was implemented on 1000 independent runs, intended to reduce the sampling bias of which a sample is selected such that some acoustic classes are not appropriate representatives among others. Such a bias is averaged out through averaging over independent runs. Each run will then result in a calibration curve described as follows.

Based on the Bayesian acoustic classification results a data set is randomly selected. Four mean angular response curves, representing the four acoustic classes, are selected. The backscatter data of the selected pings form the observed $(\mathrm{O})$ backscatter data. The modeled $(\mathrm{M})$ backscatters are to be subtracted from the observed values to make the observation vector $y=\mathrm{O}-\mathrm{M}$. As previously mentioned, the $\mathrm{O}-\mathrm{M}$ cannot directly be obtained because the modeled BS data is a function of unknown geoacoustic parameters $M_{z}, w_{2}$, and $\sigma_{2}$. The calibration curve and the geoacoustic parameters should thus be estimated simultaneously using the differential evolution (DE) optimization method. Per independent run, this will then give a calibration curve for the selected backscatter curves along with their optimized geoacoustic parameters $M_{z}, w_{2}$, and $\sigma_{2}$. This optimization process does not require known grab samples at the position of the employed backscatter curves.

The estimation process of the calibration curve was repeated 1000 times. The results are presented in Figure 3. The 1000 runs were divided into two groups each consisting of 500 curves to test the reliability and stability of the results. As indicated the general trend of the two groups are quite similar and the mean calibration curves are nearly identical; the difference between the two averaged curves is at the MBES error level of $0.1 \mathrm{~dB}$. We then use the mean curve over all 1000 runs as the ACC of the sonar system. This correction is finally applied to the observed backscatter curves of the entire survey area. The DE optimization method will then provide the three inverted geoacoustic parameters of the Brown Bank. 


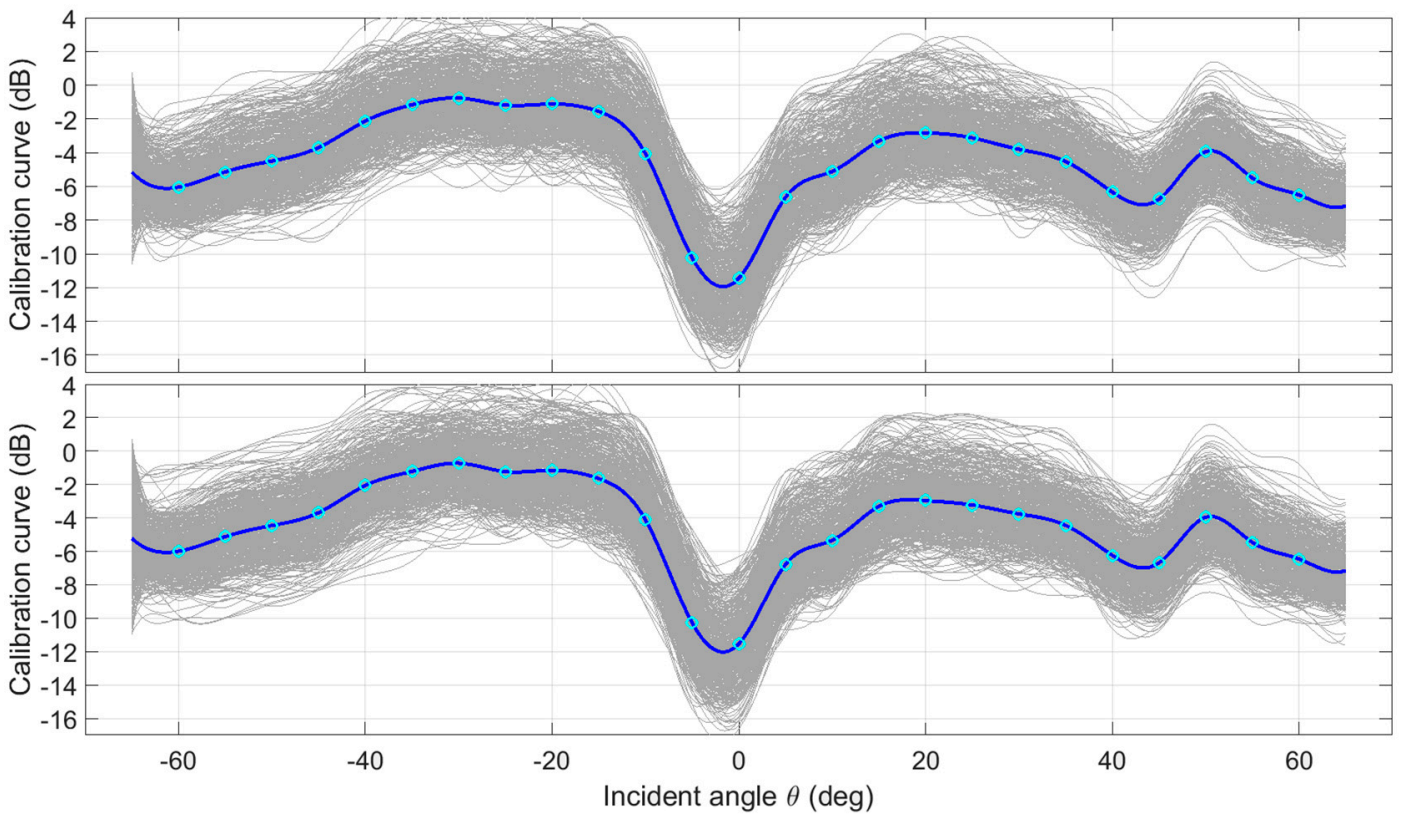

Figure 3. Calibration curve obtained from 1000 independent runs; results are presented in two frames (top and bottom) each consisting of 500 runs; in each frame the average curve is indicated in blue. Spline function consists of a series of third-order polynomials connected at knots indicated as cyan circles at 5-degree intervals.

\subsection{Estimating Geoacoustic Parameters}

The measured backscatter of the previous subsection can be corrected for the angular calibration curve. The corrected backscatter curve can then be used to invert for the geoacoustic parameters in the entire survey area. The inversion is performed over three geoacoustic parameters $M_{z}$, $w_{2}$, and $\sigma_{2}$ of the selected backscatter curve. This is done separately for the port or the starboard beams of the sonar. Use is made of the differential evolution (DE) optimization method. The unknown parameters were constrained as $-1 \leq M_{z} \leq 9,0.001 \leq w_{2} \leq 0.01$, and $0.0001 \leq \sigma_{2} \leq 0.02$. Figure 4 shows two typical mean backscatter curves for which the geoacoustic inversion was implemented to estimate $M_{z}, w_{2}$, and $\sigma_{2}$. The modeled BS curves closely follow the corrected backscatter curves after the optimization method was applied.
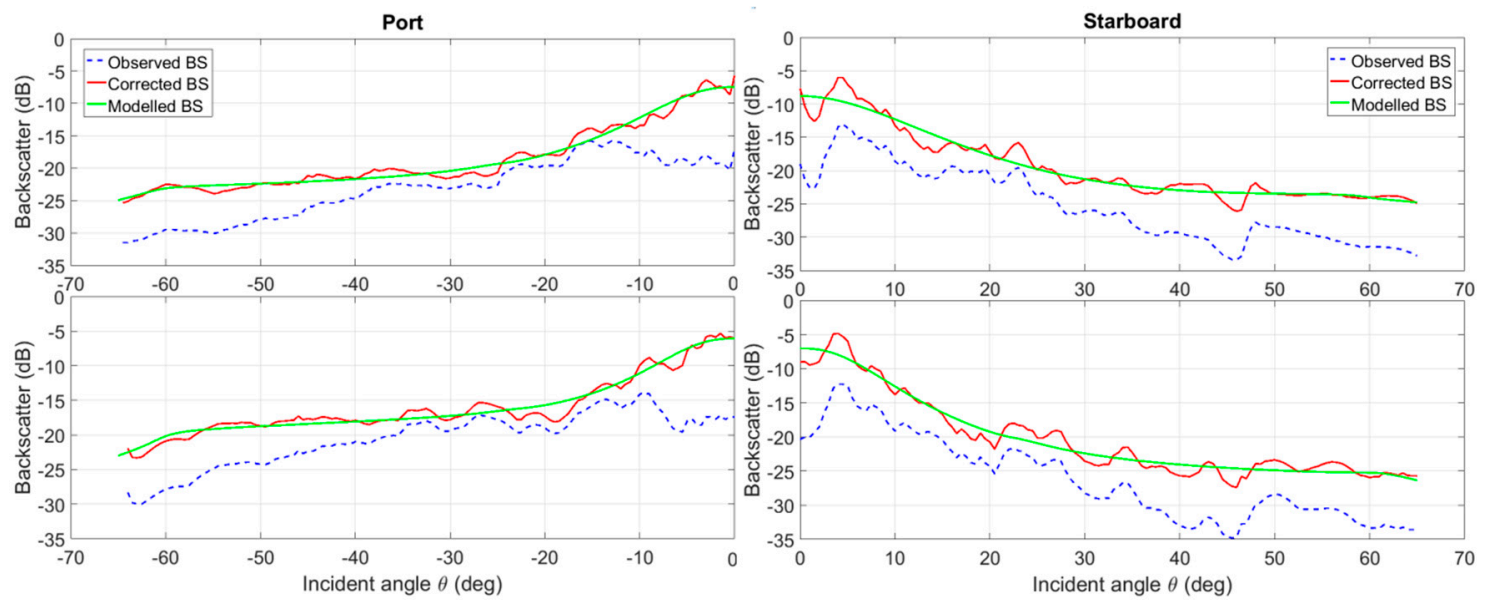

Figure 4. Two typical examples of optimization problem in which three geoacoustic parameters were searched for, Port side (left), Starboard side (right); indicated in plots are observed backscatter curve (dashed blue line), corrected backscatter curve after applying calibration curve (solid red line), and modeled backscatter curve (solid green line). 
The inverted geoacoustic parameters are presented in Figure 5. The mean grain sizes mainly range from $1-2.5$ phi with the dominant values in the range of $1.5-2$ phi (Figure $5 a$ ). This is in agreement with the grab samples collected in this survey area. The estimated mean grain sizes show high spatial variability (randomly scattered), which may indicate that the survey area has indeed almost non-distinctive and heterogeneous sedimentary composition. However, the parameters $w_{2}$ (Figure $5 b$ ) and $\sigma_{2}$ (Figure 5c) show clear spatial patterns.
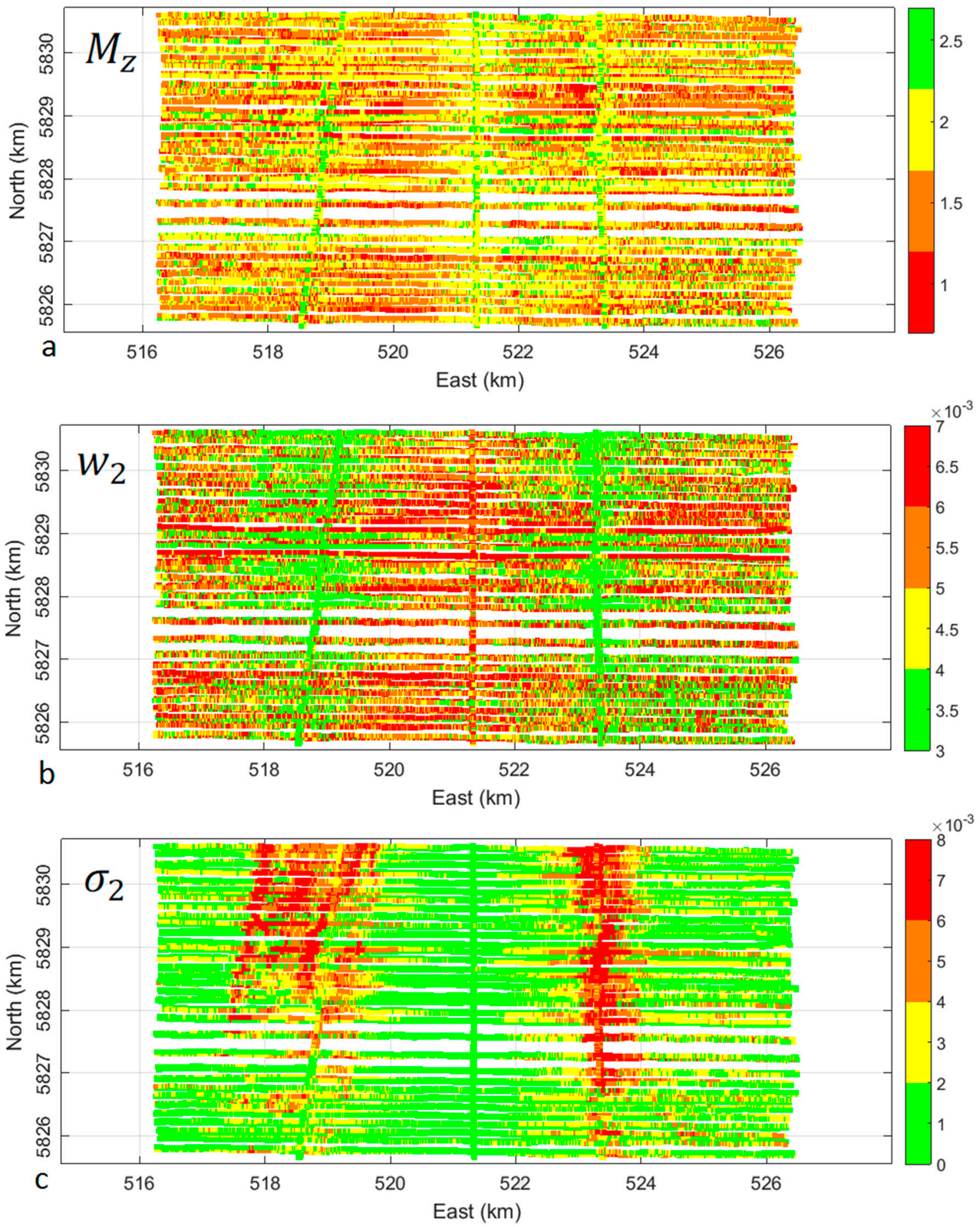

Figure 5. Inverted geoacoustic parameters of mean grain size $M_{z}(\mathbf{a})$, spectral strength $w_{2}(\mathbf{b})$, and volume scattering parameters $\sigma_{2}(\mathbf{c})$ in Brown Bank, North Sea. 
The estimated parameters have high spatial variations. This is in conjunction with the sand wave structures along with their sediment migration, which are highly variable in such a dynamic environment. To obtain a general trend of the sediment parameters, we employ the least squares bi-cubic spline approximation (LS-BICSA) method [49]. An approximation surface to the results presented in Figure 5 is given in Figure 6. Clear spatial patterns of all geoacoustic parameters can be identified in the survey area (see next section).
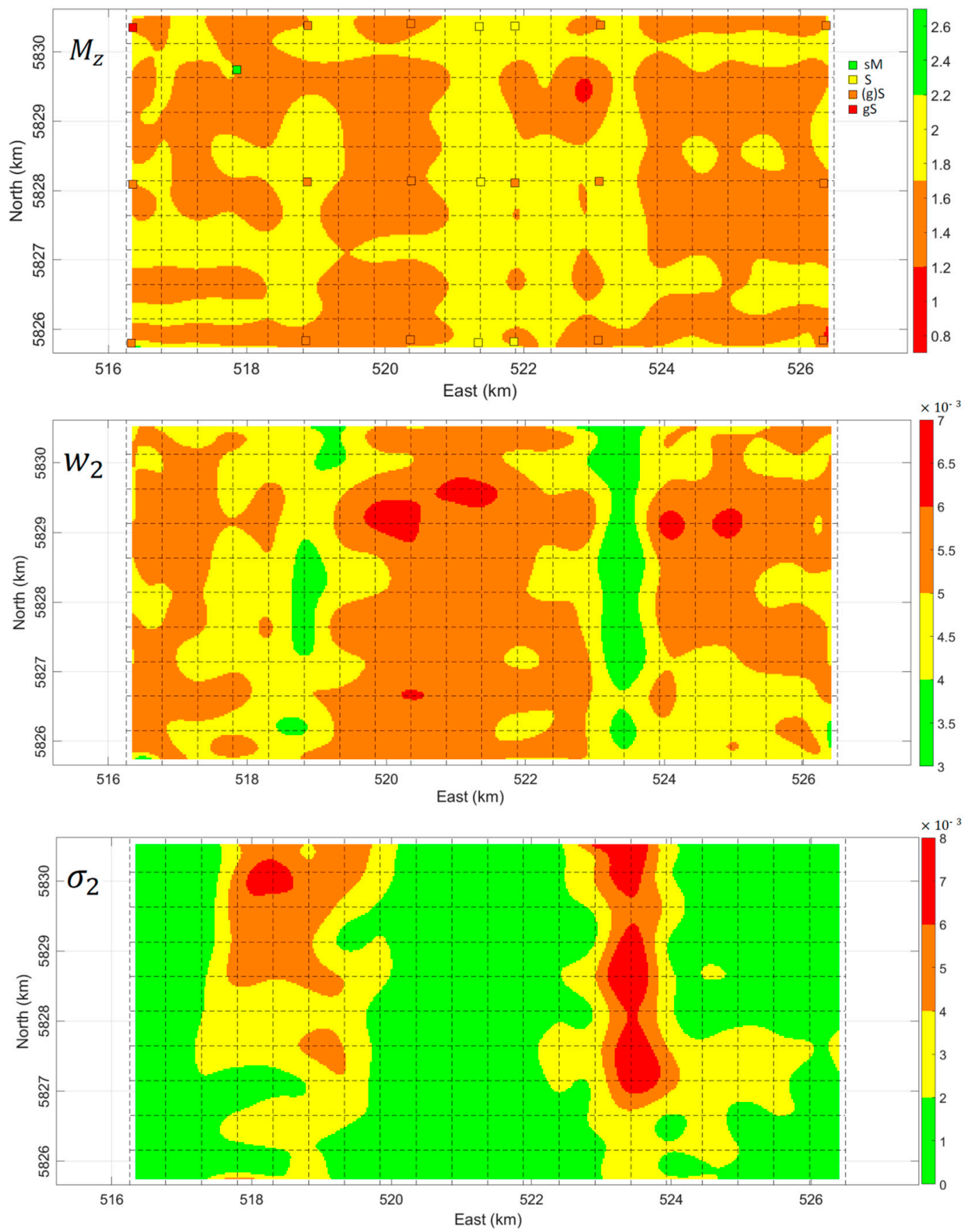

Figure 6. Smoothed maps of inverted mean grain size $M_{z}$ (top), spectral strength $w_{2}$ (middle), and volume scattering parameters $\sigma_{2}$ (bottom). Indicated in top frame also mean grain sizes of grab samples based on Folk classification scheme. Dashed line indicates square patches connected to each other using LS-BICSA method (Amiri-Simkooei et al. [49]). 


\section{Results and Discussion}

\subsection{Acoustic Classes vs. Geoacoustic Parameters}

The inverted parameters in Figure 5 show some correlation with the acoustic classes in Figure 2. To further investigate the interaction between the geoacoustic parameters and the Bayesian acoustic classes, the two datasets were geographically matched, and the occurrences of the acoustic classifications were counted. The mode of the acoustic class within a two-meter radius was used. The histogram of the geoacoustic parameters, categorized for each acoustic class, is depicted in Figure 7. For the mean grain sizes $M_{z}=1.5,2$, there is no clear distinction in acoustic classes. Although the four acoustic classes generally correspond to the full range of the estimated grain sizes, higher acoustic classes appear only for the coarsest sediments $\left(M_{z}=-0.5,0,0.5\right)$, while lower acoustic classes correspond to finest sediments $\left(M_{z}=2.5,3\right)$. Furthermore, lower and higher volume scattering parameters $\sigma_{2}$ generally correspond to lower and higher acoustic classes, respectively. The reverse holds for the spectral strength parameter $w_{2}$.
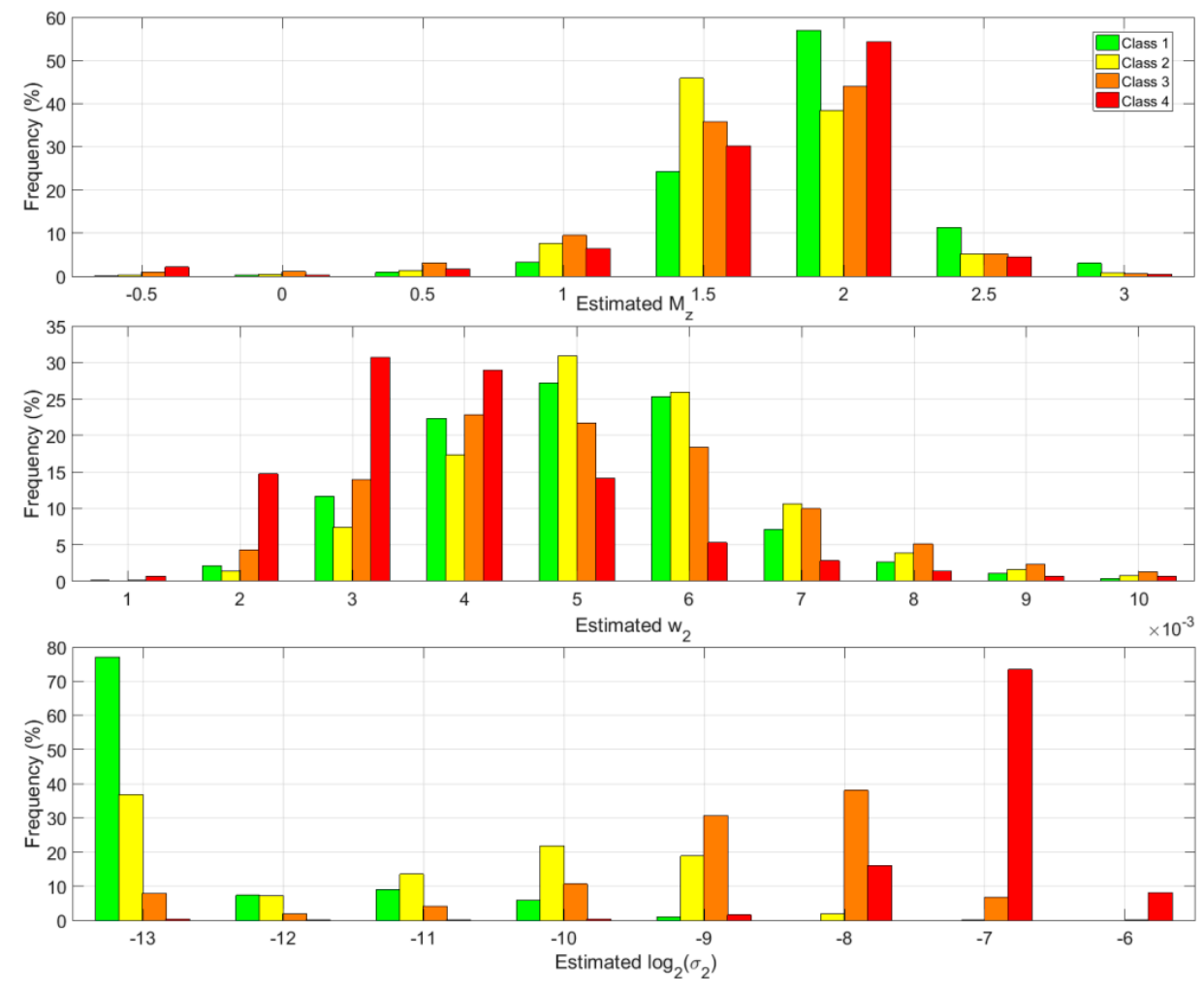

Figure 7. Histogram of inverted mean grain size $M_{z}$ (top), spectral strength $w_{2}$ (middle), and volume scattering parameter $\sigma_{2}$ in log scale (bottom) categorized versus Bayesian acoustic classes.

Figure 8 gives two examples of predicted backscatter curves for two grain size values $M_{z}=1.5$ (top) and $M_{z}=2$ (bottom) in the survey area for which the spectral strength $w_{2}$ and volume scattering parameter $\sigma_{2}$ were also inverted using the optimization method. This highlights that ground-truthing the acoustic classes should not only be attributed to the mean grain size values of grab samples. As observed, there are occasions that the backscatter values of coarser sediments (i.e., $M_{z}=1.5$ ) is less than those of finer sediments (i.e., $M_{z}=2$ ). This highlights the contribution of other (independent) geoacoustic parameters $w_{2}$ and $\sigma_{2}$ to the backscattering (see also Section 5.3). 

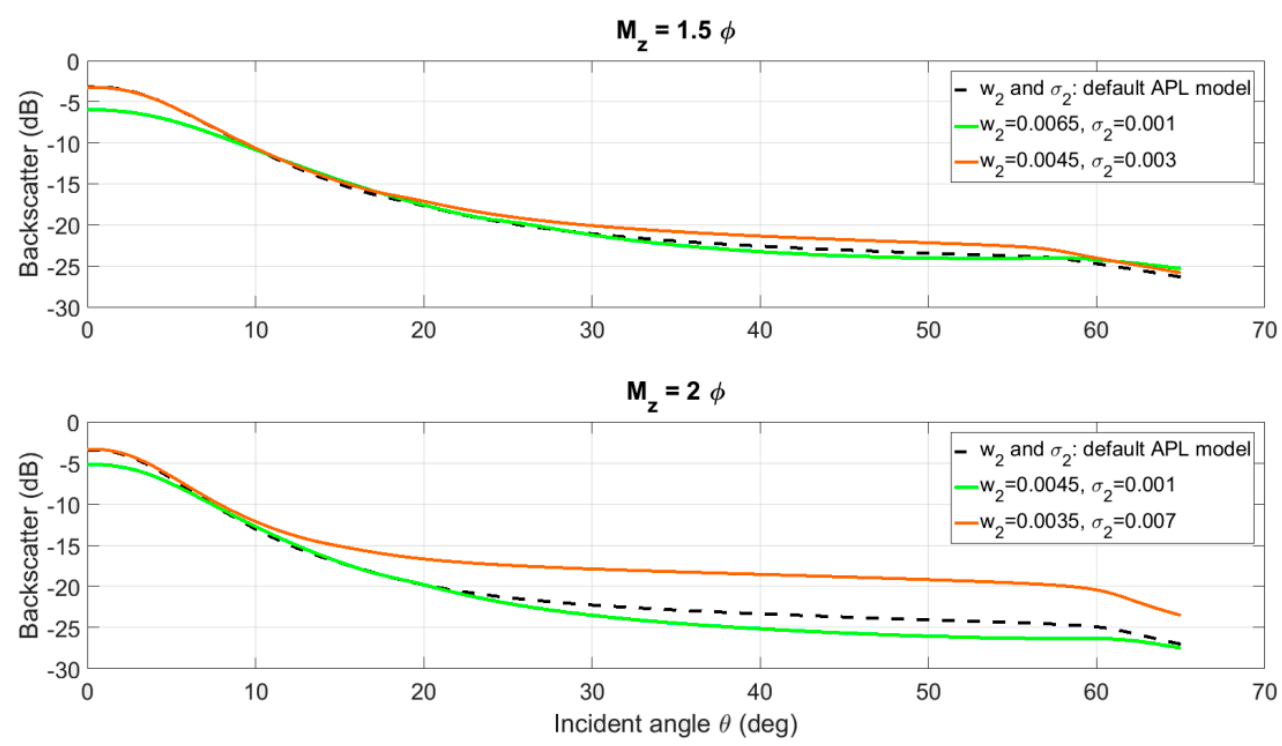

Figure 8. Examples of predicted backscatter curves of two grain size values $M_{z}=1.5 \phi$ (top) and $M_{z}=2 \phi$ (bottom) for which spectral strength $w_{2}$ and volume scattering parameter $\sigma_{2}$ were inverted using optimization method.

\subsection{Grab Sample Ground-Truthing}

The available grab samples were not used so far. Previous studies $[6,19,20,22,23]$ required grab samples either in the calibration stage or in assigning acoustic classes to sediment grain sizes. The methodology presented here does not require grab samples because the calibration curve was estimated using only observed backscatter curves. This suggests a broad range of marine applications for which the proposed method can be used, and hence opens new research areas in such applications, especially for the modern multi-frequency MBES systems.

The grab samples are used as ground truth data to compare to the inverted mean grain sizes. Having conceptually different sediment classification schemes makes the geological classification of sediments an inexact experience. Ground-truthing of the inverted grain size values can thus be prone to imperfections, especially in an almost homogenous sedimentary area like Brown Bank. Our observations indicate that there is no one-to-one correspondence between the mean grain size and the Folk classification scheme. For each Folk class, there exists a broad range of grain size values, and therefore, different Folk classes can have similar grain sizes. This is also further verified if the US geological survey (USGS) Folk classification scheme is compared with the British geological survey (BGS). The two schemes seem to be considerably different for the grabs taken in this area (Figure 9). Many grab samples classified as (g)S in USGS change to $S$ in the BGS scheme. Therefore, such considerations should also be borne in mind when ground-truthing results. 


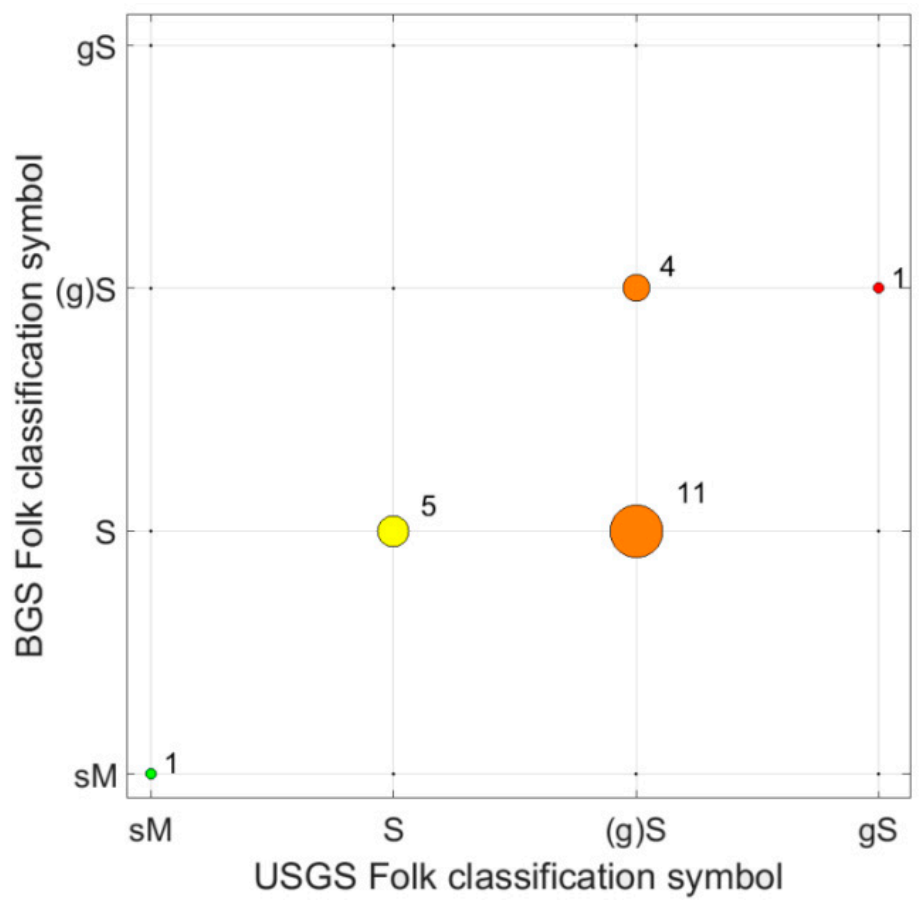

Figure 9. BGS Folk classification versus USGS Folk classification of grab samples from Brown Bank; numbers indicate number of occurrences for grab samples.

The mean grain size is usually computed from $M_{z}=\left(\phi_{16}+\phi_{50}+\phi_{84}\right) / 3$, where $\phi_{16}, \phi_{50}$, and $\phi_{84}$ represent the size at the 16, 50, and 84 percentiles of the sample by weight [50]. Four Folk classes were identified for the grabs taken (see [36]). However, their $M_{z}$ values did not vary significantly, ranging from $1.50 \phi$ to $1.74 \phi$. Instead other grain size distribution parameters like sorting, skewness, and kurtosis could contribute as criteria for ground-truthing. They also show that the backscatter value around the grab samples correlates with the percentage of the grab contents having a diameter greater than $0.5 \mathrm{~mm}$, which is in agreement with the findings in [51] who found a positive correlation between backscatter and shell and gravel percentage.

These observations raise the question whether the above parameters can also contribute when computing the mean grain size. We propose a modified formula that considers the information (sorting, skewness, and kurtosis) in the tails of the grain size distribution. Our proposal is

$$
M_{z}=\frac{\phi_{2}+\phi_{16}+\phi_{50}+\phi_{84}+\phi_{98}}{5}
$$

where $\phi_{2}$ and $\phi_{98}$ can accordingly be defined. The above percentiles at the numerator of Equation (11) nearly correspond to the cumulative normal distribution at $\mu-2 \sigma, \mu-\sigma, \mu, \mu+\sigma$, and $\mu+2 \sigma$, respectively, with $\mu$ the mean and $\sigma$ the standard deviation of the normal distribution. If Equation (11) is used, the range of variations for $M_{z}$ increases from $1.37 \phi$ to $2.11 \phi$, which clearly includes the $M_{z}=1.50 \phi$ (slightly gravelly sand) and $M_{z}=2 \phi$ (sand), to be consistent with Folk classes. Further comparison of the inverted mean grain sizes with those computed from Equation (11) for the grab samples is shown in Figure 10. A positive trend is indicated, even though this area is composed of almost homogenous sediments. 


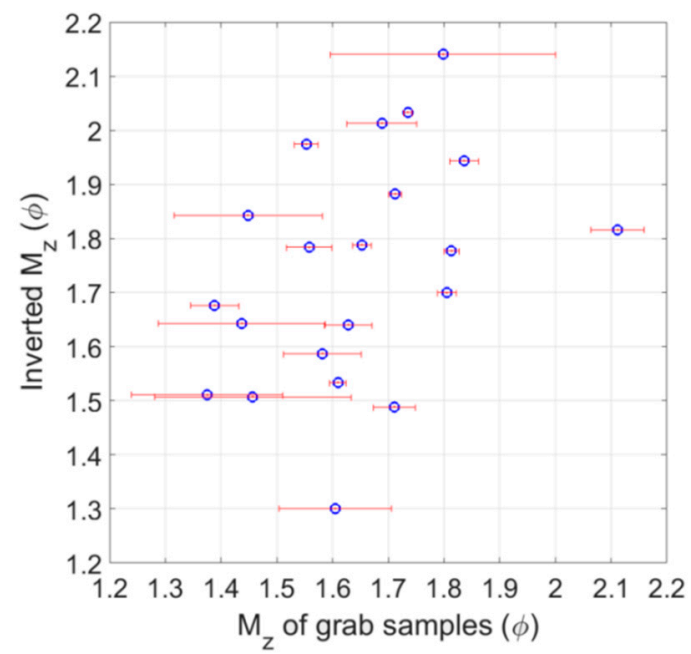

Figure 10. Averaged (over three replicates) mean grain size and standard deviation of grab samples versus their corresponding inverted values using optimization method.

\subsection{Importance of Inversion for Three Parameters}

The results indicate that the search for at least three geoacoustic parameters is required. The empirical models relate the roughness parameter $w_{2}$ and the volume scattering parameter $\sigma_{2}$, to the mean grain size $M_{z}$ [40]. These relations are known to be rather weak as there is a considerable range of variations in these two parameters and hence they are not much correlated with $M_{z}$ (APL-UW model, [25]). Therefore, optimization was performed by using the three parameters $M_{z}, w_{2}$, and $\sigma_{2}$.

To further elaborate on this issue, the optimization method was implemented only for the mean grain size, while keeping $w_{2}$ and $\sigma_{2}$ fixed to their average values or to those predicted by the model. We thus search only for $M_{z}$ values in the optimization method. The estimated $M_{z}$ values are presented in Figure 11. As indicated the range of $M_{z}$ variations has been significantly increased compared to the results presented in Figure 6 (significant green areas having $M_{z} \cong 2.5$ and red areas having $M_{z} \cong 1$ areas appeared), which cannot be justified based on the grab sample analysis. These areas indeed correspond to those having smallest and largest $\sigma_{2}$, respectively, and to some extent having largest and smallest $w_{2}$ values. Ignoring these two geoacoustic parameters may thus overestimate or underestimate the inverted mean grain sizes.

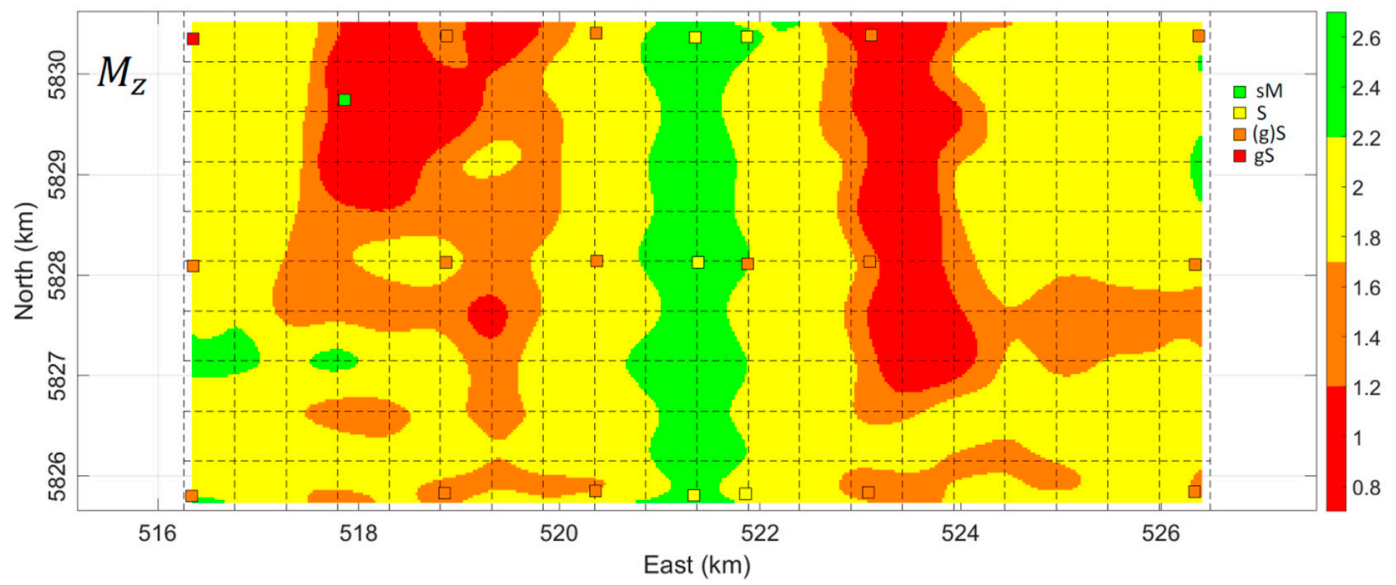

Figure 11. Smoothed maps of inverted mean grain size $M_{z}$ along with Folk classes of grab samples when spectral strength $w_{2}$ and volume scattering parameter $\sigma_{2}$ were kept fixed to their average values. 
There was one triple of grab samples (Station 23) having a smaller mean grain size than the rest of the grab samples $\left(M_{z}=4.40 \pm 1.40\right)$. The grab at this station was composed of very fine particles that were compacted and stuck together. For most grab samples, clumps of particles sticking together could be brushed lightly in order for them to be sieved. The grab samples from Station 23, however, had to be crushed through various sieve sizes with force. The particle size analysis (PSA) then indicated small grain sizes for this grab sample. Although the grab sample was identified to be fine-grained, the backscatter curve around this sample showed rather large values, corresponding to higher acoustic class. Koop et al. [36] attribute this inconsistency to the above observation. Regarding this grab sample, another observation is highlighted as follows.

The acoustic class around this grab sample is mainly four (high class), which in principle indicates coarse sediment. This contradiction is investigated in the following two inversion cases.

Case 1 -We invert only for the parameter $M_{z}$, while $w_{2}$ and $\sigma_{2}$ are kept fixed to their average values. The inverted mean grain size would be around $M_{z}=-0.5 \phi$, which still indicates coarse sediment and hence is inconsistent with the grab sample (Figure 12a).

Case 2-The inversion is accomplished over the three parameters $M_{z}, w_{2}$ and $\sigma_{2}$, as we did in this paper. The estimated mean grain size is around $M_{z}=2.5 \phi$, which indicates fine sediment, congruent to the grab sample (Figure 12b). Figure 12c shows that the volume scattering parameter $\sigma_{2}$ is estimated to be high around this grab sample.

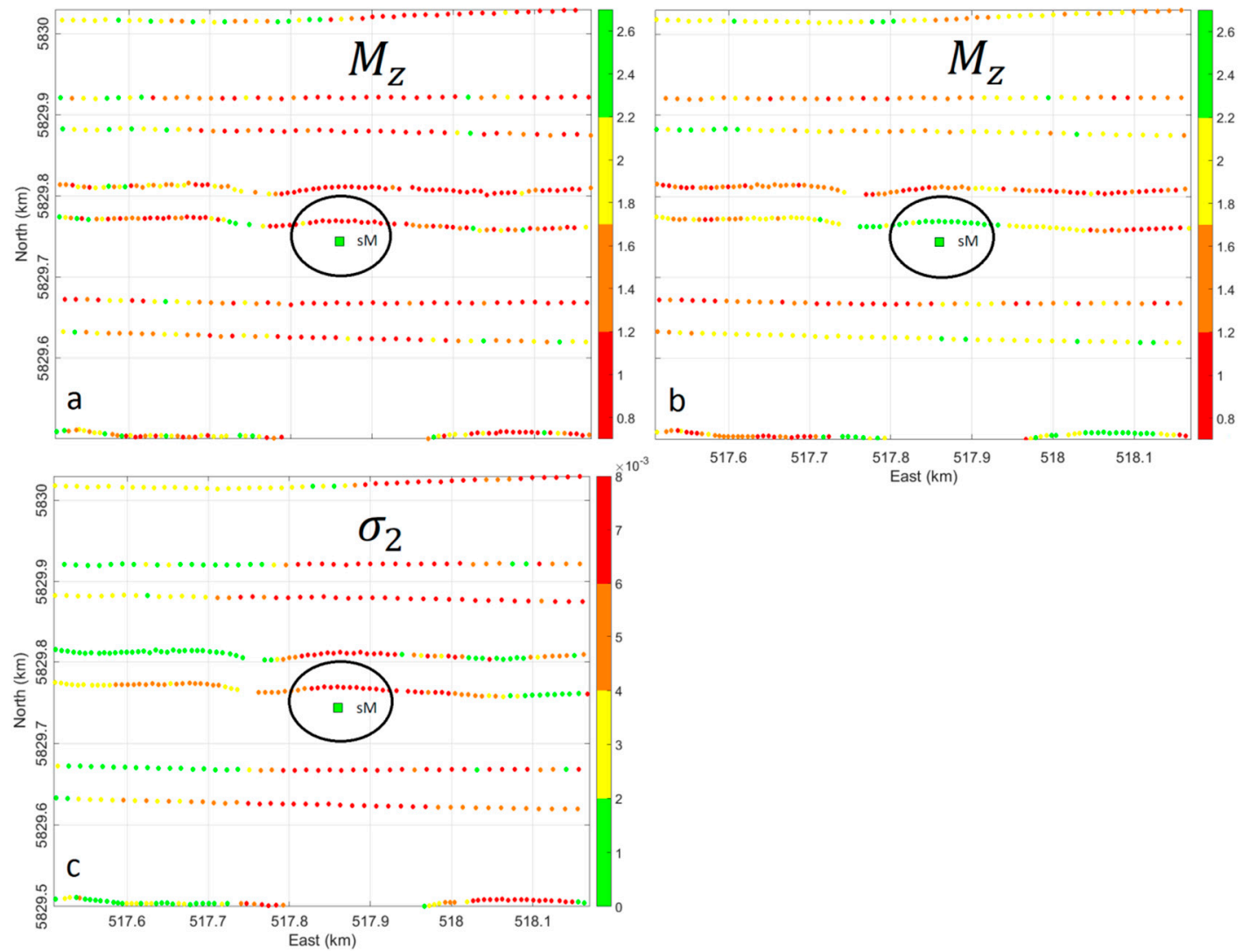

Figure 12. Zoom-in map of inverted geoacoustic parameters using optimization method applied to mean backscatter curve around grab sample 23 (indicated inside ellipses with green square and $M_{z}=4.40 \pm 1.40$ ); (a) mean grain size $M_{z}$ for which search was performed only over $M_{z}$ (fixing $w_{2}$ and $\left.\sigma_{2}\right)$, (b) mean grain size $M_{z}$, and (c) volume scattering parameters $\sigma_{2}$ for which search was performed over three parameters $M_{z}, w_{2}$, and $\sigma_{2}$.

This observation is in conjunction with the results presented in Figure 8 that higher backscatter values should not necessarily be attributed to coarser sediment, especially in almost non-distinctive 
environments such as the Brown Bank. Other geoacoustic parameters, here $\sigma_{2}$, can also have significant contribution to the backscattering. With such a low frequency signal (i.e., $30 \mathrm{kHz}$ ), this indicates that the backscatter presented here includes significant sub-bottom information as it penetrates into the sediment and hence provides insight into the top layers of sediment up to a few decimeters of depth $(\sim 0.50 \mathrm{~m})$.

\subsection{Brown Bank Sediment Composition}

The spatial pattern in Figure 6 (top) shows that most of the entire area is dominated either as $1.2<M_{z} \leq 1.7$ (orange) or as $1.7<M_{z} \leq 2.2$ (yellow). This is in agreement with the Folk classification of the grab samples which shows that the dominant sediment types in this area is either sand (S) or slightly gravelly sand $(\mathrm{g}) \mathrm{S}$.

The geoacoustic parameter variations, over the structure of the Brown Bank, are depicted in Figure 13. The general observation is that the crest of the bank is composed mainly of softer sediment (sand), while the trough consists of mainly coarser sediment-i.e., (g)S—with occasions of softer sediments, as presented in Figure 5a. The crest of the bank has higher roughness scattering parameters, but lower volume scattering parameter. A reverse situation holds in the trough of the sand bank.
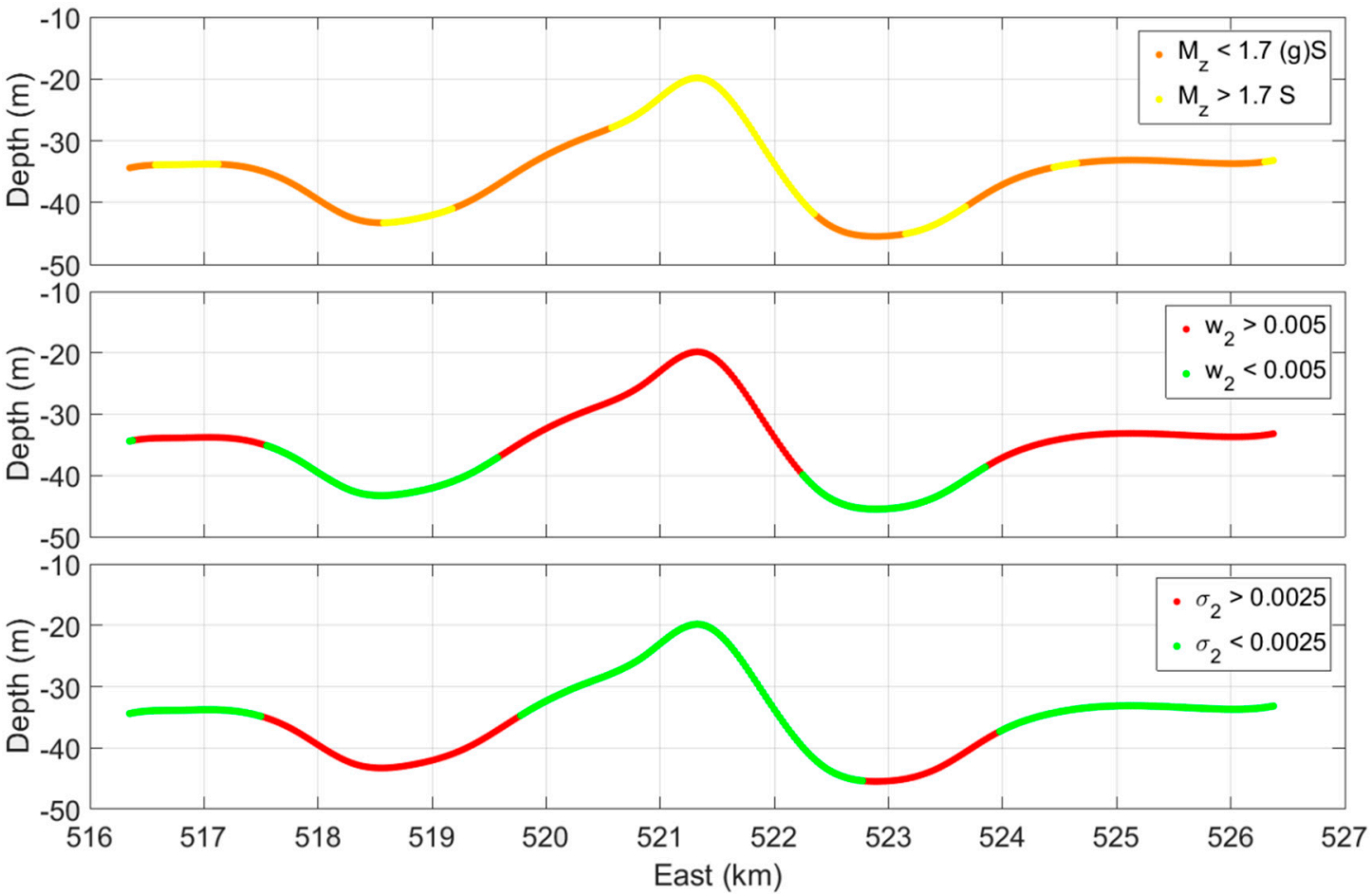

Figure 13. Large scale variations of estimated mean grain size $M_{z}$ (top), spectral strength $w_{2}$ (middle), and volume scattering parameter $\sigma_{2}$ (bottom) over Brown Bank structure in eastward direction (results averaged along north axis).

There are two main contributors to seabed surface roughness. (1) The grain size of sediments, as a microscale contributor, and (2) The seafloor surface structure or bed forms (e.g., ripple structures), as a macroscale contributor. For softer sediment $\left(M_{z}>3\right)$, it is assumed that sediment volume scattering is dominant, while for coarser sediment $\left(M_{z}<3\right)$ roughness scattering is the main contributor to backscattering (APL-UW model, [25]). This is however not what we observe based on the results presented in Figures 6 and 13. It is because the two dominant sediments, $\mathrm{S}$ vs. (g)S having both $M_{z}<3$, do not much differ in their mean grain sizes. This indicates that seafloor surface structure is likely the main source of surface scattering and not $M_{z}$. The smallest-scale bed forms are sand ripples with wavelengths of several centimeters. Based on the video footage, these ripples are present at the Brown 
Bank. The general conclusion is that sand ripples are more abundant and more defined on the crest than in the troughs (Figure 14). This further confirms our statement that ripple patterns can be a significant contributor to the roughness of the crest.

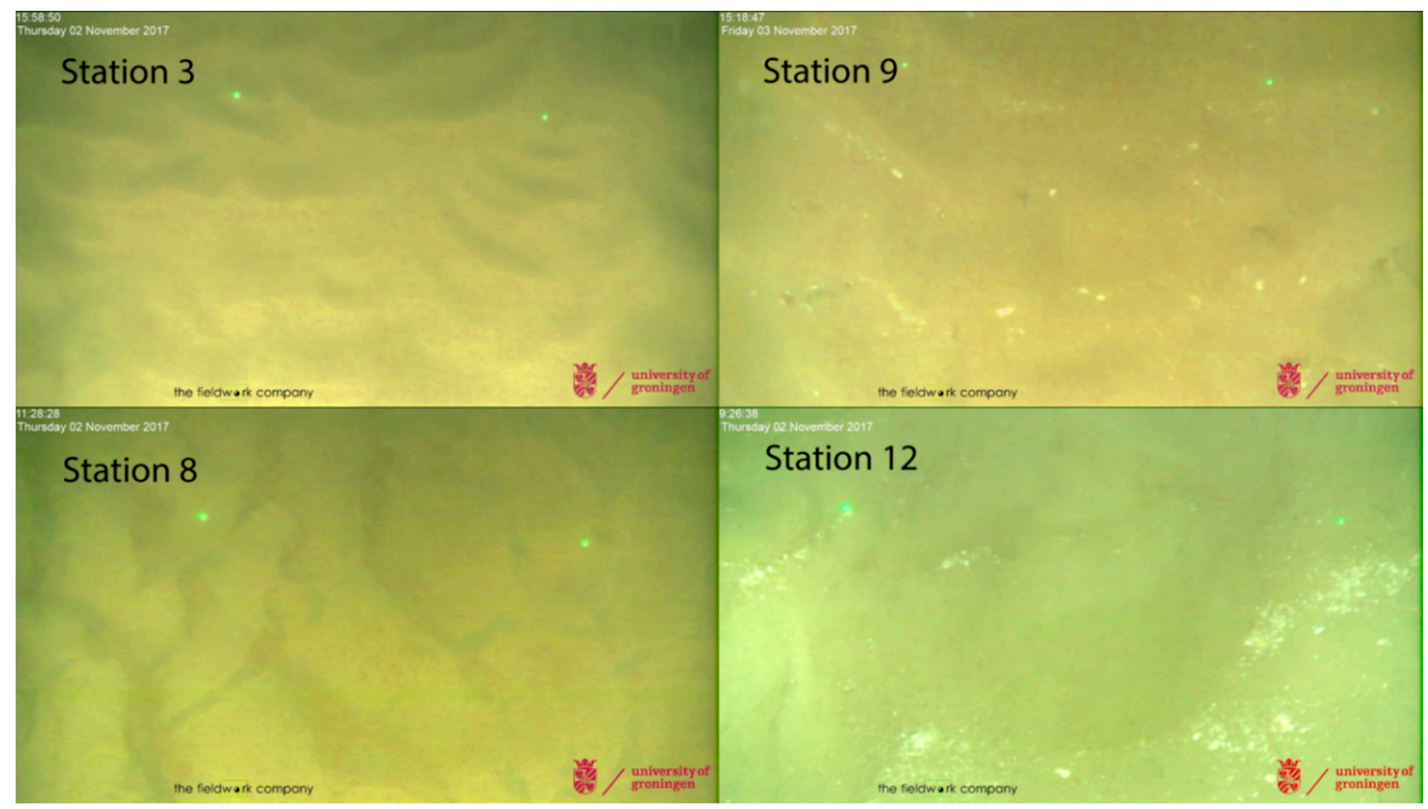

Figure 14. Video data presented as still images from stations 9 and 12 (in troughs) and 3 and 8 (on crest). Indicated in pictures are also two green dots representing a distance of $\sim 20 \mathrm{~cm}$, sand ripples having wavelengths of $\sim 5 \mathrm{~cm}$ and other surficial structures/compositions.

A final remark on the large-scale sedimentary composition of Brown Bank is in order. As for mean grain size sorting on tidal ridges, de Swart and Yuan [52] find that in the case of symmetrical tidal ridges the coarsest sediments usually occur on the crest. The Brown Bank is not symmetrical, and hence the coarsest sediments are expected at the steeper side of the ridge. This is in agreement with both modeled results, using a bimodal sediment mixture, and observations from sandbanks of the Belgian continental shelf [53]. Walgreen et al. [54] also modeled tidal sand wave formation using a bimodal sediment distribution and found similar results. That is, coarser grains sorted to the crest. However, when they added a constant "flood flow" to the main tidal current then the coarser grains sorted towards the shoreward side of the bank. The results of the above model were in agreement with field observations of van Dijk et al. [48] from the Brown Bank, who reported sorted medium sand on the crest but a muddy surface sediment having gravely sediments on the troughs. Our mean grain size ground truth data and the inverted mean grain sizes in Figure 5 (top) also confirm this observation. In the crest, we observed more sorted sediment mainly sand $\left(M_{z} \approx 2 \phi\right)$, while the troughs show more spread sediment types, from coarse to fine $\left(M_{z} \approx 1-2.5 \phi\right)$.

\section{Conclusions}

Seafloor sediment characterization using multibeam echosounder (MBES) backscatter data has been the subject of intensive research in the last two decades. The drawback of current model-based sediment characterization methods is that they need ground truth data, such as grab samples in reference areas, to calibrate the MBES sonars. This is because the observed backscatter curve (OBC) cannot directly be coupled to the modeled backscatter curve $(\mathrm{MBC})$ due to the uncalibrated sonar characteristics. We presented a methodology to characterize the seafloor sediments without grab samples. This method estimates the calibration curve of the sonar using only OBCs. The least squares cubic spline approximation (LS-CSA) method was implemented in an optimization algorithm based on the differential evolution. In the calibration stage, the calibration curve along with the 
geoacoustic parameters of the selected backscatter curves were simultaneously estimated in the differential evolution optimization method.

Having estimated the calibration curve, it is possible to apply the optimization method to the OBC corrected for the calibration effect. The results indicated that a search for three geoacoustic parameters, i.e., the sediment mean grain size, roughness parameter, and volume scattering parameter, was required. The inverted mean grain sizes were in agreement with grab samples, indicating reliability and stability of the proposed method. When the optimization was performed only over the mean grain sizes, the inverted $M_{z}$ values were underestimated or overestimated. It is noted that the proposed method was applied to an MBES dataset in an almost non-distinctive sedimentary environment with a low frequency signal $(30 \mathrm{kHz})$. Future work should investigate the performance of the method in different geological environments having more distinctive sediments and with different frequencies.

We observed that higher backscatter values, and thereby higher acoustic classes, should not only be attributed to (slightly) coarser sediment, especially in almost non-distinctive sedimentary environments such as the Brown Bank. Other geoacoustic parameters could also have significant contribution to the backscattering. Here, the roughness parameter and volume scattering parameter were significantly correlated with acoustic class numbers. Apart from the mean grain size, roughness scattering can also be attributed to the bed form morphology of the seafloor-ripple structure, for instance.

The grab samples showed that sediment types had a small range of variation in their mean grain size values. It was thus rather difficult to compare the inverted $M_{z}$ values with grab samples. Some discrepancies can be explained that ground-truthing of inverted results can be an uncertain experience in almost non-distinctive sedimentary environments. It is difficult to discriminate between the $M_{z}$ values of the two dominant sediment types 'sand' versus 'slightly gravelly muddy sand' in this area, or to determine which sediment is coarser or finer. Such imperfections, attributed not only to the inverted $M_{z}$ values in the optimization process but also to those of the taken grab samples, need further investigation in future research studies.

Author Contributions: Conceptualization, A.R.A.-S., L.K., M.S. and D.G.S.; Data curation, L.K. and K.J.v.d.R.; Formal analysis, A.R.A.-S., L.K., K.J.v.d.R., M.S. and D.G.S.; Funding acquisition, D.G.S. and M.S.; Investigation, A.R.A.-S., L.K. and K.J.v.d.R.; Methodology, A.R.A.-S., L.K., K.J.v.d.R., M.S. and D.G.S.; Project administration, A.R.A.-S., L.K., M.S. and D.G.S.; Resources, A.R.A.-S., L.K. and K.J.v.d.R.; Software, A.R.A.-S. and L.K.; Supervision, M.S. and D.G.S.; Validation, A.R.A.-S., L.K., K.J.v.d.R. and M.S.; Visualization, A.R.A.-S. and L.K.; Writing-original draft, A.R.A.-S., L.K. and K.J.v.d.R.; Writing—review \& editing, A.R.A.-S., L.K., K.J.v.d.R., M.S. and D.G.S.

Funding: This research is part of the multi-disciplinary research project DISCLOSE. DISCLOSE is a joint venture of the Delft University of Technology, the University of Groningen, the Royal Netherlands Institute for Sea Research, as well as the North Sea Foundation. DISCLOSE is funded by the Gieskes Strijbis Fonds.

Acknowledgments: We would like to thank RobWitbaard for being the chief scientist during the data gathering cruise and the crew of the NIOZ vessel the Pelagia for their assistance during the acquisition of the data. Karline Soetaert of NIOZ is acknowledged for her role in organizing the cruise, Sarah O'Flynn for taking the grab samples, and Tom Ysebaert for coordinating the particle size analysis of the grab samples. Peter van Breugel was key in performing the particle size analysis in the NIOZ lab. We also thank Leendert Dorst and Daniëlle van Kuijk of the Hydrographic Service within the Royal Netherlands Navy for making full coverage bathymetry data of the Brown Bank area available. We acknowledge the Gieskes-Strijbis Fonds for the financial support of the DISCLOSE project, within which this research took place.

Conflicts of Interest: The authors declare no conflict of interest.

\section{References}

1. Diesing, M.; Mitchell, P.; Stephens, D. Image-based seabed classification: What can we learn from terrestrial remote sensing? ICES J. Mar. Sci. 2016, 73, 2425-2441. [CrossRef]

2. Diesing, M.; Thorsnes, T. Mapping of cold-water coral carbonate mounds based on geomorphometric features: An object-based approach. Geosciences 2018, 8, 34. [CrossRef]

3. Marsh, I.; Brown, C. Neural network classification of multibeam backscatter and bathymetry data from Stanton Bank (Area IV). Appl. Acoust. 2009, 70, 1269-1276. [CrossRef] 
4. Ojeda, G.Y.; Gayes, P.T.; Van Dolah, R.F.; Schwab, W.C. Spatially quantitative seafloor habitat mapping: Example from the northern South Carolina inner continental shelf. Estuar. Coast. Shelf Sci. 2004, 59, $399-416$. [CrossRef]

5. Clarke, J.H.; Danforth, B.; Valentine, P. Areal seabed classification using backscatter angular response at $95 \mathrm{kHz}$. In Proceedings of the SACLANTCEN Conf on High Frequency Acoustics in Shallow Water, Lerici, Italy, 30 June-4 July 1997; pp. 243-250.

6. Fonseca, L.; Mayer, L. Remote estimation of surficial seafloor properties through the application angular range analysis to multibeam sonar data. Mar. Geophys. Res. 2007, 28, 119-126. [CrossRef]

7. Lamarche, G.; Lurton, X.; Verdier, A.-L.; Augustin, J.-M. Quantitative characterisation of seafloor substrate and bedforms using advanced processing of multibeam backscatter-Application to Cook Strait, New Zealand. Cont. Shelf Res. 2011, 31, S93-S109. [CrossRef]

8. Hamilton, L.J. Clustering of cumulative grain size distribution curves for shallow-marine samples with software program CLARA. Aust. J. Earth Sci. 2007, 54, 503-519. [CrossRef]

9. Hamilton, L.J.; Parnum, I. Acoustic seabed segmentation from direct statistical clustering of entire multibeam sonar backscatter curves. Cont. Shelf Res. 2011, 31, 138-148. [CrossRef]

10. Brown, C.J.; Smith, S.J.; Lawton, P.; Anderson, J.T. Benthic habitat mapping: A review of progress towards improved understanding of the spatial ecology of the seafloor using acoustic techniques. Estuar. Coast. Shelf Sci. 2011, 92, 502-520. [CrossRef]

11. Brown, C.J.; Todd, B.J.; Kostylev, V.E.; Pickrill, R.A. Image-based classification of multibeam sonar backscatter data for objective surficial sediment mapping of Georges Bank, Canada. Cont. Shelf Res. 2011, 31, S110-S119. [CrossRef]

12. Eleftherakis, D.; Amiri-Simkooei, A.; Snellen, M.; Simons, D.G. Improving riverbed sediment classification using backscatter and depth residual features of multi-beam echo-sounder systems. J. Acoust. Soc. Am. 2012, 131, 3710-3725. [CrossRef] [PubMed]

13. Snellen, M.; Gaida, T.C.; Koop, L.; Alevizos, E.; Simons, D.G. Performance of Multibeam Echosounder Backscatter-Based Classification for Monitoring Sediment Distributions Using Multitemporal Large-Scale Ocean Data Sets. IEEE J. Ocean. Eng. 2018, 1-14. [CrossRef]

14. Misiuk, B.; Diesing, M.; Aitken, A.; Brown, C.J.; Edinger, E.N.; Bell, T. A spatially explicit comparison of quantitative and categorical modeling approaches for mapping seabed sediments using random forest. Geosciences 2019, 9, 254. [CrossRef]

15. Stephens, D.; Diesing, M. Towards quantitative spatial models of seabed sediment composition. PLoS ONE 2015, 10, e0142502. [CrossRef] [PubMed]

16. Brown, C.J.; Beaudoin, J.; Brissette, M.; Gazzola, V. Multispectral multibeam echo sounder backscatter as a tool for improved seafloor characterization. Geosciences 2019, 9, 126. [CrossRef]

17. Buscombe, D.; Grams, P.E. Probabilistic substrate classification with multispectral acoustic backscatter: A comparison of discriminative and generative models. Geosciences 2018, 8, 395. [CrossRef]

18. Gaida, T.C.; Tengku Ali, T.A.; Snellen, M.; Amiri-Simkooei, A.R.; Van Dijk, T.A.G.P.; Simons, D.G. A multispectral Bayesian classification method for increased acoustic discrimination of seabed sediments using multi-frequency multibeam backscatter data. Geosciences 2018, 8, 455. [CrossRef]

19. Simons, D.G.; Snellen, M. A Bayesian approach to seafloor classification using multi-beam echo-sounder backscatter data. Appl. Acoust. 2009, 70, 1258-1268. [CrossRef]

20. Amiri-Simkooei, A.; Snellen, M.; Simons, D.G. Riverbed sediment classification using multi-beam echo-sounder backscatter data. J. Acoust. Soc. Am. 2009, 126, 1724-1738. [CrossRef]

21. Jackson, D.R.; Winebrenner, D.P.; Ishimaru, A. Application of the composite roughness model to high-frequency bottom backscattering. J. Acoust. Soc. Am. 1986, 79, 1410-1422. [CrossRef]

22. Fonseca, L.; Brown, C.; Calder, B.; Mayer, L.; Rzhanov, Y. Angular range analysis of acoustic themes from Stanton Banks Ireland: A link between visual interpretation and multibeam echosounder angular signatures. Appl. Acoust. 2009, 70, 1298-1304. [CrossRef]

23. Santos, R.; Rodrigues, A.; Quartau, R. Acoustic remote characterization of seabed sediments using the Angular Range Analysis technique: The inlet channel of Tagus River estuary (Portugal). Mar. Geol. 2018, 400, 60-75.

24. Collier, J.; Brown, C. Correlation of sidescan backscatter with grain size distribution of surficial seabed sediments. Mar. Geol. 2005, 214, 431-449. [CrossRef] 
25. APL-UW Model. High-Frequency Ocean Environmental Acoustics Models Handbook; APL-UW Technical Report, No. APL-UW 9407; Williams, K.L., Ed.; Scientific Research: Wuhan, China, 1994. Available online: http://www.dtic.mil/docs/citations/ADB199453 (accessed on 26 June 2019).

26. Bartels, R.H.; Beatty, J.C.; Barsky, B.A. Hermite and Cubic Spline Interpolation. In An Introduction to Splines for Use in Computer Graphics and Geometric Modeling; Morgan Kaufmann: San Francisco, CA, USA, 1998; Chapter 3; pp. 9-17.

27. Chen, W.K. Feedback, Nonlinear, and Distributed Circuits; CRC Press: Boca Raton, FL, USA, 2009; pp. 9-20, ISBN 978-1-4200-5881-9.

28. Reinsch, C.H. Smoothing by Spline Functions. Numer. Math. 1976, 10, 177-183. [CrossRef]

29. Runge, C. Über empirische Funktionen und die Interpolation zwischen äquidistanten Ordinaten. Zeitschrift für Mathematik und Physik 1901, 46, 224-243.

30. Burden, R.L.; Faires, J.D.; Reynolds, A.C. Numerical Analysis, 6th ed.; Brooks/Cole: Boston, MA, USA, 1997; pp. 120-121.

31. Lyche, T. Discrete Cubic Spline Interpolation. BIT 1976, 16, 281-290. [CrossRef]

32. Lawson, C.L.; Hanson, R.J. Solving Least Squares Problems; Prentice Hall: Upper Saddle River, NJ, USA, 1974.

33. Luenberger, D.G. Least-Squares Estimation. Optimization by Vector Space Methods; John Wiley \& Sons: Hoboken, NJ, USA, 1997; pp. 78-102.

34. Teunissen, P.J.G. Adjustment Theory: An Introduction; Series on Mathematical Geodesy and Positioning; Delft University Press: Delft, The Netherlands, 2000.

35. Zangeneh-Nejad, F.; Amiri-Simkooei, A.R.; Sharifi, M.A.; Asgari, J. Cycle slip detection and repair of undifferenced single-frequency GPS carrier phase observations. GPS Solut. 2017, 21, 1593-1603. [CrossRef]

36. Koop, L.; Amiri-Simkooei, A.R.; van der Reijden, K.J.; O’Flynn, S.; Snellen, M.; Simons, D.G. Seafloor classification in a sand wave environment on the Dutch Continental Shelf using multibeam echosounder backscatter data. Geosciences 2019, 9, 142. [CrossRef]

37. De Boor, C. A Practical Guide to Splines, rev. ed.; Springer: New York, NY, USA, 2001.

38. Alevizos, E.; Snellen, M.; Simons, D.G.; Siemes, K.; Greinert, J. Acoustic discrimination of relatively homogeneous fine sediments using Bayesian classification on MBES data. Mar. Geol. 2015, 370, 31-42. [CrossRef]

39. Eleftherakis, D.; Snellen, M.; Amiri-Simkooei, A.; Simons, D.G.; Siemes, K. Observations regarding coarse sediment classification based on multi-beam echo-sounder's backscatter strength and depth residuals in Dutch rivers. J. Acoust. Soc. Am. 2014, 135, 3305-3315. [CrossRef]

40. Hamilton, E. Prediction of deep-sea sediment properties: State-of-the-art. In Deep-Sea Sediments, Physical and Mechanical Properties; Inderbitzen, A.L., Ed.; Plenum Press: New York, NY, USA, 1974; pp. 1-43.

41. Snellen, M.; Simons, D.G. An assessment of the performance of global optimisation methods for geoacoustic inversion. J. Comput. Acoust. 2008, 16, 199-223. [CrossRef]

42. Snellen, M.; Siemes, K.; Simons, D.G. Model-based sediment classification using single-beam echosounder signals. J. Acoust. Soc. Am. 2011, 129, 2878-2888. [CrossRef] [PubMed]

43. Snellen, M.; Eleftherakis, D.; Amiri-Simkooei, A.R.; Koomans, R.L.; Simons, D.G. An inter-comparison of sediment classification methods based on multi-beam echo-sounder backscatter and sediment natural radioactivity data. J. Acoust. Soc. Am. 2013, 134, 959-970. [CrossRef] [PubMed]

44. Knaapen, M.A. Sandbank occurrence on the Dutch continental shelf in the North Sea. Geo-Mar. Lett. 2009, 29, 17-24. [CrossRef]

45. Flemming, N.C. The Scope of Strategic Environmental Assessment of North Sea Areas SEA3 and SEA2 in Regard to Prehistoric Archaeological Remains. Report TR 014; Department of Trade and Industry: Hong Kong, China, 2002.

46. Laban, C. Seabed mapping in the Dutch sector of the North Sea. Sea Technol. 2006, 47, 47-51.

47. Ward, I.; Larcombe, P. Determining the preservation rating of submerged archaeology in the post-glacial southern North Sea: A first-order geomorphological approach. Environ. Archaeol. 2008, 13, 59-83. [CrossRef]

48. Van Dijk, T.A.; van Dalfsen, J.A.; van Lancker, V.; van Overmeeren, R.A.; van Heteren, S.; Doornenbal, P.J. Benthic habitat variations over tidal ridges, North Sea, the Netherlands. In Seafloor Geomorphology as Benthic Habitat; Elsevier: Amsterdam, The Netherlands, 2012; pp. 241-249.

49. Amiri-Simkooei, A.R.; Hosseini-Asl, M.; Safari, A. Least squares 2D bi-cubic spline approximation: Theory and applications. Measurement 2018, 127, 366-378. [CrossRef] 
50. Folk, R.L.; Ward, W.C. Brazos River bar [Texas]; a study in the significance of grain size parameters. J. Sedim. Res. 1957, 27, 3-26. [CrossRef]

51. Simons, D.G.; Snellen, M.; Ainslie, M.A. A multivariate correlation analysis of high-frequency bottom backscattering strength measurements with geotechnical parameters. IEEE J. Ocean. Eng. 2007, 32, 640-650. [CrossRef]

52. De Swart, H.E.; Yuan, B. Dynamics of offshore tidal sand ridges, A review. Environ. Fluid Mech. 2018, 1-25. [CrossRef]

53. Roos, P.C.; Hulscher, S.; Van Der Meer, F.; Van Dijk, T.; Wientjes, I.G.; van den Berg, J. Grain size sorting over offshore sandwaves: Observations and modeling. In Proceedings of the 5th IAHR Symposium on River, Coastal and Estuarine Morphodynamics, Enschede, The Netherlands, 17-21 September 2007.

54. Walgreen, M.; De Swart, H.E.; Calvete, D. A model for grain-size sorting over tidal sand ridges. Ocean Dyn. 2004, 54, 374-384. [CrossRef]

(C) 2019 by the authors. Licensee MDPI, Basel, Switzerland. This article is an open access article distributed under the terms and conditions of the Creative Commons Attribution (CC BY) license (http://creativecommons.org/licenses/by/4.0/). 